
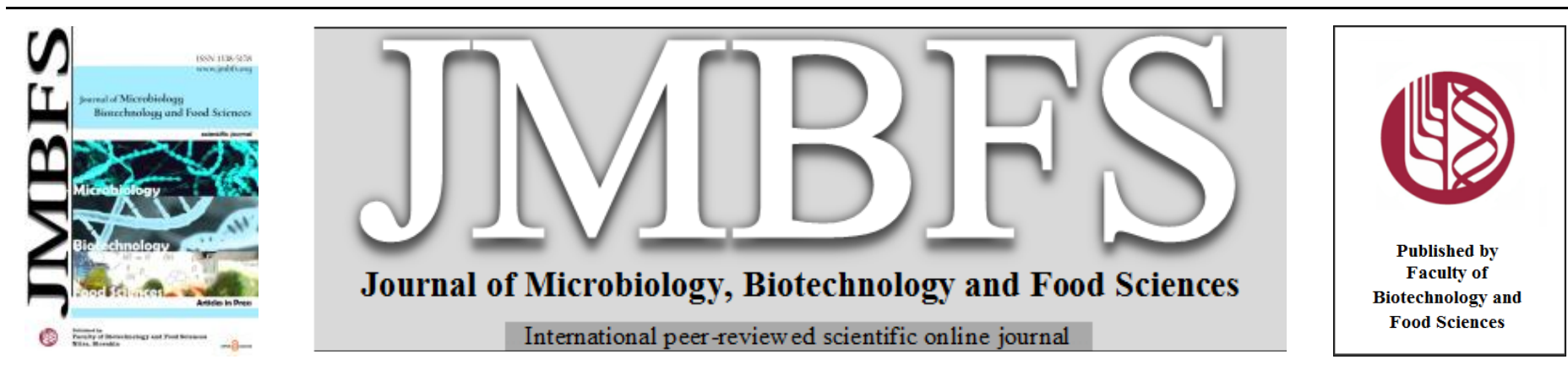

\title{
CURRENT SCENARIO OF SARS-CORONAVIRUS 2: EPIDEMIOLOGY; POST-COVID-19 AND GLOBAL IMPACTS
}

\author{
Vishnu Priya Sampath ${ }^{a *}$, Prasannaraj Govindaraj ${ }^{b}$, Ramasamy Subbiah $^{c}$, Makesh Mohan $^{d}$
}

\begin{abstract}
Address(es):
a State-Key Laboratory for Mechanical Behavior of Materials, School of Material Science \& Engineering, Xi'an Jiaotong University, Xi'an 710049, China.

${ }^{\mathrm{b}}$ Neurochemistry Laboratory, Department of Neurological Sciences, Christian Medical College and Hospital, Vellore 632004, Tamil Nadu, India.

${ }^{\mathrm{c}}$ Cardiac Hypertrophy Laboratory, Department of Molecular Biology, School of Biological Sciences, Madurai Kamaraj University, Madurai 625021, Tamil Nadu, India.

${ }^{\mathrm{d}}$ Department of Physics, National Institute of Technology, Karnataka (NITK) Surathkal 575025, Karnataka, India.
\end{abstract}

*Corresponding author: vishnulifebt@gmail.com

https://doi.org/10.15414/jmbfs.4066

\section{ARTICLE INFO}

Received 11. 12. 2020

Revised 17. 6. 2021

Accepted 29. 6. 2021

Published 1. 12. 2021

Regular article

OPEN $\partial_{\text {ACCESS }}$

\section{ABSTRACT}

Severe Acute Respiratory Syndrome Coronavirus 2 (SARS-CoV-2) is a highly contagious strain of coronavirus that causes Coronavirus Disease 2019 (COVID-19) infection, which has distressed the world's health and wealth. This Global Pandemic outbreak has affected public health enormously at various customs. The investigation of SARS-CoV-2 is still at infancy; however, based on the available reports, this review gives an overview of the epidemiology, genomic landscape, diversity of SARS-CoV-2, viral genome pathogenic interactions, associating factors for COVID-19 infections, post-COVID-19, disease manifestations with their comorbidities, the major obstacles and the preventive measures along with current vaccine strategies of SARS-CoV-2. This review also summarizes all the relevant evidence of COVID-19 illness, which can provide valuable information on the SARS-CoV-2 genome and its mode of action strategies, thus delivering additional knowledge about COVID-19.

Keywords: SARS-CoV-2, COVID-19, Genetic factors, Post-COVID, Disease manifestations, Herd immunity, COVID-19 Vaccines

\section{BACKGROUND}

Virus life cycle mutation is one of the natural phenomena; perhaps not alter the virulence of the virus pathogenicity. The novel coronavirus (COVID 19; later named by WHO) is a pandemic disease caused by a family of the severe acute respiratory syndrome (SARS) in humans named SARS-CoV-2 (Coronavirus-2); the member of seventh RNA $\beta$ coronavirus (Zhu et al., 2020). Furthermore, the genomic content of RNA is tightly packed and enclosed by a protein shell. RNA of COVID-19 has been mutating unconditionally based on physiological and environmental factors. Currently, researchers are working in the fields of epidemiology (Smith et al., 2013; Smith et al., 2014; Sanjuán \& DomingoCalap, 2016; Shen et al., 2004; Wang et al., 2020; Chan et al., 2013), molecular expressions (Smith et al.,2013; Chan et al.,2013; Banu et al., 2020; Kaul, 2020), and clinical medical history (Zhu et al., 2020; Shen et al., 2004) of SARS-CoV-2, and were updated their consequences reported regularly. However, evaluation of these parameters is quite essential to track and solve this viral infection worldwide (Zhu et al., 2020; Chan et al., 2013). Even though, only a few studies were discussed about the genetics phenomenon of the host on COVID-19 infections. Additionally, the mutation rate of SARS-CoV-2 is very low compared to other viral mutations, even though these mutations haven't altered the functional characteristic of SARS-CoV-2. However, the functional characterization of specialized viral isolates was showed significant changes in the viral pathogenicity (Yao et al., 2020). Therefore, we are focusing on the SARS-CoV-2 genome; associated factors for host interactions with the mutational impacts of COVID-19 from the virtual investigation of genomic data were overviewed. Moreover, the perception of the noteworthy sceneries of the SARS-CoV-2 post-infection, disease manifestations, and deliberate features of vaccine development was highlighted.

\section{THE GENOME LANDSCAPE OF SARS-COV-2}

\section{Strain Allelic diversity of SARS-CoV-2 genome}

The evolution of SARS-CoV-2 exists in three distinct variants; based on their amino acid alignment, the genomic content of SARS-CoV-2 has been distinguished in three types A, B, and C (Forster et al., 2020). In type-A, nearly $96.2 \%$ of sequences are matched with bat coronavirus compared with the human virus (Zhou et al., 2020). Therefore, type A originated from Wuhan coming under the out-groups of ancestral prominent viral genomes and mutated in two clusters B and C. Briefly, identical mutation arose in T-allele T29025C, mutated into two sub clustered forms B and C. Moreover, in Wuhan (China), America and Europe consist of a significant level of type A and C (ancestral viral genome). Besides, type A predominant exists only in Wuhan, whereas type C existed only in Europe and America. A mutated genome of type B only found in East Asia derived from type A. Indeed, another interesting fact that the type B genome of SARS-CoV-2 not mutated inside and outside of East Asia may come due to tropical resistance power and immunological power (Forster et al., 2020). Additionally, scientists from the Peking University and Institute Pasteur of Shanghai reported that two strains of SARS-CoV-2 from 103 populations, S-type as original strain from Wuhan, and the L-type evolved from S-type, predominantly present in the US. The antagonistic L-type widely spread and act as a potent virulent than S-type. Moreover, the Wuhan strain of S-type was restricted to adapt and mutate. Further, these surface proteins emerged as L-type (Tang et al., 2020).

Recently, the unique cluster of the genome of $\mathrm{CoV}$ predominant clade I/A3i was identified in India, which clinically correlated with $41 \%$ of SARS-CoV-2 and in global genomes matched with $3.5 \%$. It is suggested that the cluster of A3i were evolved from the common ancestor of SARS-CoV-2 on Feb 2020 during a pandemic outbreak, and the distinctive mutations have occurred on their viral genome were confirmed by epidemiological valuations. Additionally, the virulence clade I/A3i were isolated from the states of Maharashtra, Tamil Nadu, Telangana, and Delhi. However, presently A2a is the most predominant type of SARS-CoV-2 in India; A3i may evolve from A2a (Banu et al., 2020).

\section{Host-COVID-19 interactions}

The genome size of coronaviruses is $30-33 \mathrm{~kb}$ with 3 'exonuclease activity during replication; trend to have the lowest mutation rate due to larger genome size compared to other RNA viruses. According to the Baltimore classification, the positive - strand of SARS-CoV-2 with RNA dependent RNA polymerases has the intrinsic polymerase fidelity activity to determine the initial mutation rate during the central dogma process (Smith et al., 2013; Sanjuán \& Domingo-Calap, 2016). In the SARS-CoV-2 genome, a spike protein ( $S$ protein) diversity is responsible for host interactions, specificity, and pathogenicity. The occurrences of mutation in S protein induce the variety of mutations, which deals with hostspecific interactions and functional expressions. Shen et al. (2004) reported that a single amino acid mutation in spike protein hampers its maturation, essential functions of cell-cell fusion, and virions assembly. However, the occurrences of these mutations 'aren't changing the virulence of the ancestral strain, the impacts SARS-CoV-2 virion are reflected in all the mutated strains. Therefore, these 
mutational impacts of SARS-CoV-2 genome analysis are highly needed by utilizing submitted genomic variations, landscape variations with drug effectiveness.

\section{HOW CAN GENOMIC VARIATIONS IN SARS-COV-2 CONTRIBUTE AS A PATHOGEN?}

\section{Genomic organization of SARS-CoV-2}

The genomic structural characterization of coronaviruses $(\mathrm{CoV})$ is $80-120 \mathrm{~nm}$ in size, single-positive stranded RNA viruses consist of four divergence groups, including $\alpha, \beta, \delta$, and $\gamma$-coronavirus (Wang et al., 2020). Among these four viruses, $\beta$-coronavirus of SARS-CoV-2 and MERS-CoV (Middle East Respiratory Syndrome) is responsible for pulmonary illness in humans (Zhu et al., 2020). The mechanism of SARS-CoV-2 is initiated by a binding receptor of angiotensin-converting enzyme 2 (ACE 2) through the $S$ protein domain and causes infection to the target cells. The diagrammatic representation of SARSCoV-2 interactions with host genome ACE 2 binding domain represented in Figure 1.

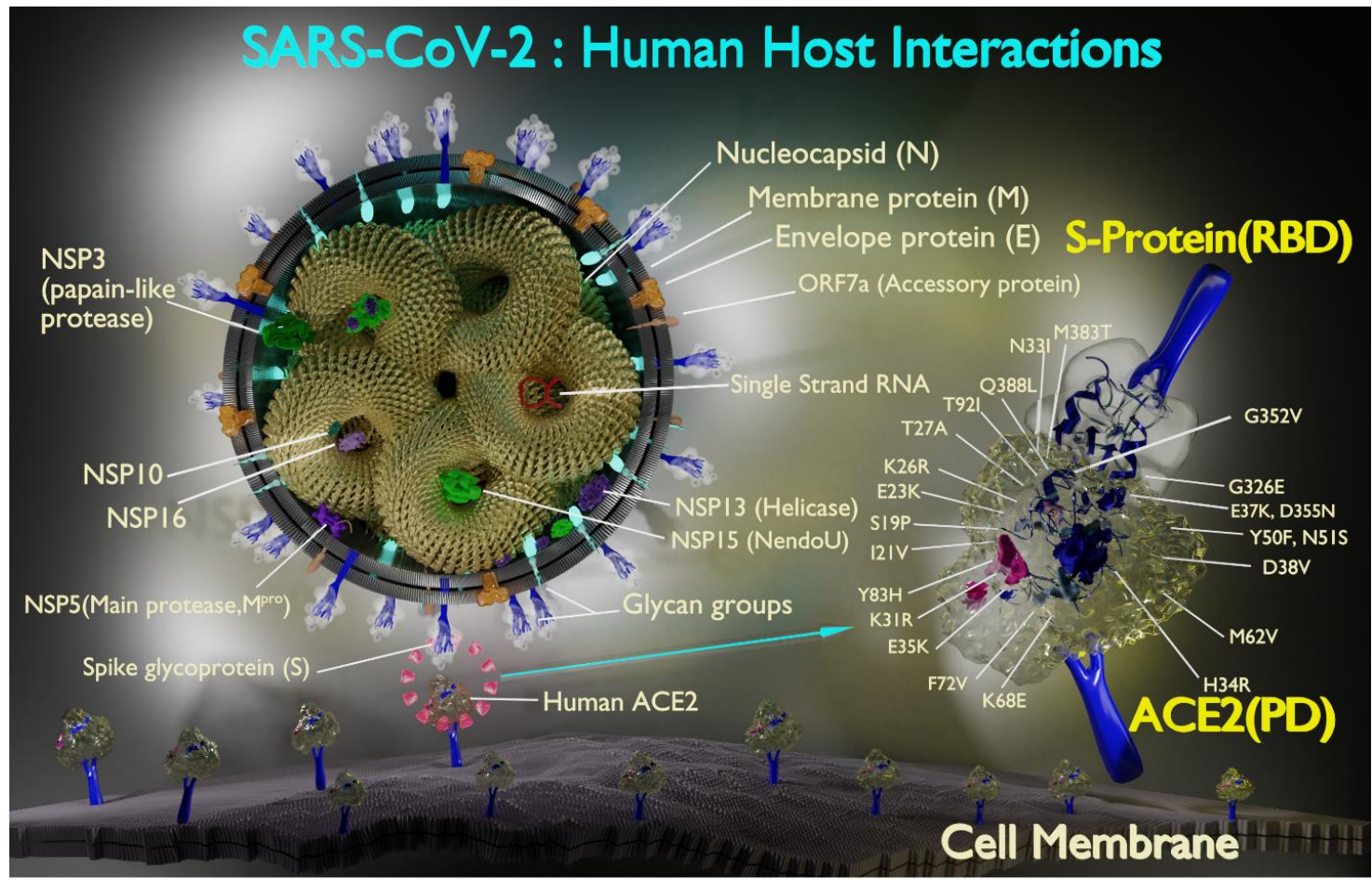

Figure 1 Diagramatic representation of SARS-CoV-2 interactions with human host ACE2 receptors

The structural features of COVID-19 capped with 5' end and consist of a base of $\sim 26.2$ to $31.7 \mathrm{~kb}$ with ten open reading frames (ORFs). The replication proteins are located at the first part of ORF (nsp 1-16), and the last part of ORFs consist of structural genes in order of S-E-M-N and middle region accessory genes are located at a variable number of ORFs. Frameshift occurs in ORF1a and ORF1b creates two polypeptides: ppla and pplab encode a viral chymotrypsin protease (3CLpro) / main protease (Mpro) with additionally papain hooked on 16nsps.
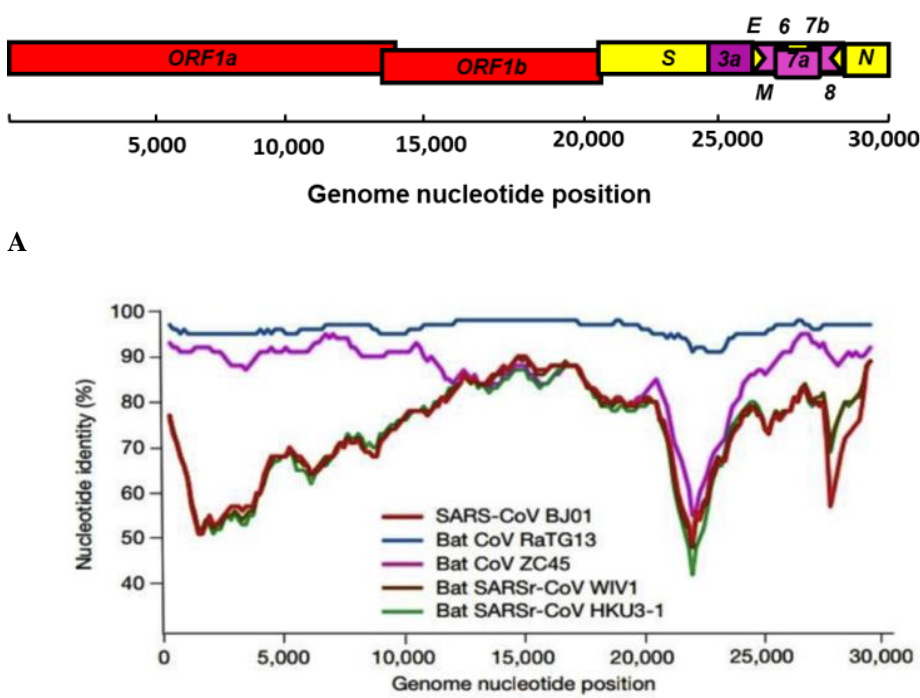

Figure 2 Genomic representation of SARS-CoV-2, (a) the coding and noncoding region of SARS-CoV-19, (b) Genomic characterization of COVID-19 and their similarity origin (Adopted from Zhou et al., 2020).

\section{MEMBRANE ASSOCIATION WITH ACE RECEPTOR}

Inside the helical nucleocapsid, the RNA genome is packed and covered by a lipid bilayer derived from the host. Furthermore, there are four membrane proteins involved for host-pathogen interactions; the spike protein $(\mathrm{S})$, the envelope protein $(\mathrm{E})$, the membrane protein $(\mathrm{M})$, the nucleocapsid protein $(\mathrm{N})$ are encrypted by ORFs10,11. Also, hemagglutinin esterase (HE) is present in some $\beta$-coronaviruses. The host interaction and virion releases are determined initiated through $\mathrm{S}$ protein and the viral assembly is carried out via $\mathrm{M}$ and $\mathrm{E}$ (Smith et al., 2013; Sanjuán \& Domingo-Calap, 2016). The complete genome profile of SARS-CoV-2 and their similarity origin characterization were represented in Figure 2 (Zhou et al.,2020).

The membrane of SARS-CoV-2 consists of four membrane proteins; among that the structural protein the glycoprotein present in abundantly; it extends to the bilayer membrane, while a small portion present in amino-terminal $\left(\mathrm{NH}_{2}\right)$ end and an elongated portion present in the cytoplasm at carboxyl-terminal $(\mathrm{COOH})$. The replication of SARS-CoV-2 comprises of the complex phenomenon of vira and cellular proteins, which take place in the cytoplasmic membrane and utilizes the host nucleus proteins for their replication process. $\mathrm{N}$ and $3 \mathrm{~b}$ of SARS-CoV-2 proteins and two forms of $\mathrm{N}$ and nsp1 Arteriviruses being identified in the hos nucleolus of infected patients (Enjuanes et al., 2006; Hiscox et al., 2001; Wurm et al., 2001; Yuan et al., 2005; Tijms et al., 2002)

Furthermore, the peplomers are glycoprotein present in the S-protein, thus mainly neutralize the host antibodies and participates in molecular interactions. The assembly of viral particles is initiate by M-protein at the intracellular membrane (Mousavizadeh \& Ghasemi, 2020; De Haan et al., 1998; Woo et al., 2010; Boheemen et al., 2012). The remarkable features of the SARS-CoV-2 genome comprise three important criteria: (i) human receptor ACE is optimized binder for SARS-CoV-2; (ii) the furin cleavage of S protein inserting 12 nucleotides at the peripheral membrane of S1-S2 cleavage site; (iii) the O-linked glycans at the site of membrane adherence on the peripheral membrane (Li, 2016; Andersen et al., 2020)

\section{REPLICATION MACHINERY MECHANISM}

The initial reorganization was carried by $\mathrm{S}$-protein protease, named as TMPRSS2. The SARS-CoV-2 genome of RNA enters through the cytoplasmic 
membrane, which ensued the central dogma events forming a large protein assembly encoded by the replicase gene $(20-\mathrm{kb})$ made up of cellular and $\sim 16$ subunits of virus. The viral replication machinery and viral progeny releases were represented in Figure 3. The enzymes of RNA dependent RNA polymerase, RNA helicase, endo, 3'to 5' exo-ribonucleases, 2'O-ribose methyltransferases, phosphodiesterases, ADP ribose 1'-phosphatase and proteases are involved in these events. The viral genome act as a template and utilizing a replicase enzyme for synthesizing their viral replicates to start via negative-strand intermediates to releases viral offspring and their mRNA. The genomic mRNAs are further undergone translation events to synthesis structural and accessory proteins. Furthermore, these structural proteins are endured post-translationa modifications in Endoplasmic Reticulum-Golgi Intermediate (ERGI). Moreover,
$\mathrm{N}$-protein produces nucleocapsid that is adhered to by viral offspring. In contrast, membrane-bound structural proteins are merged with viral progenies and further forming an assembly of virions released in the form of budding into ERG complex. The latter viral progenies are discharged from affected cells via Golgi. However, part of SARS-CoV-2 directly extents to the plasma membrane without virion assembly. Simultaneously, the $\mathrm{S}$ protein surface initiates the union of the affected cell with neighborhood, non-infected cells, which form substantial multinucleated syncytia. Therefore, it facilitates the self-regulation of extracellular viral contagion spread and escapes from immune scrutiny (Hoffmann et al., 2020; Guo et al., 2020; Sola et al.,2015; Ziebuhr, 2002; Almazán et al., 2006; Peiris, 2016)

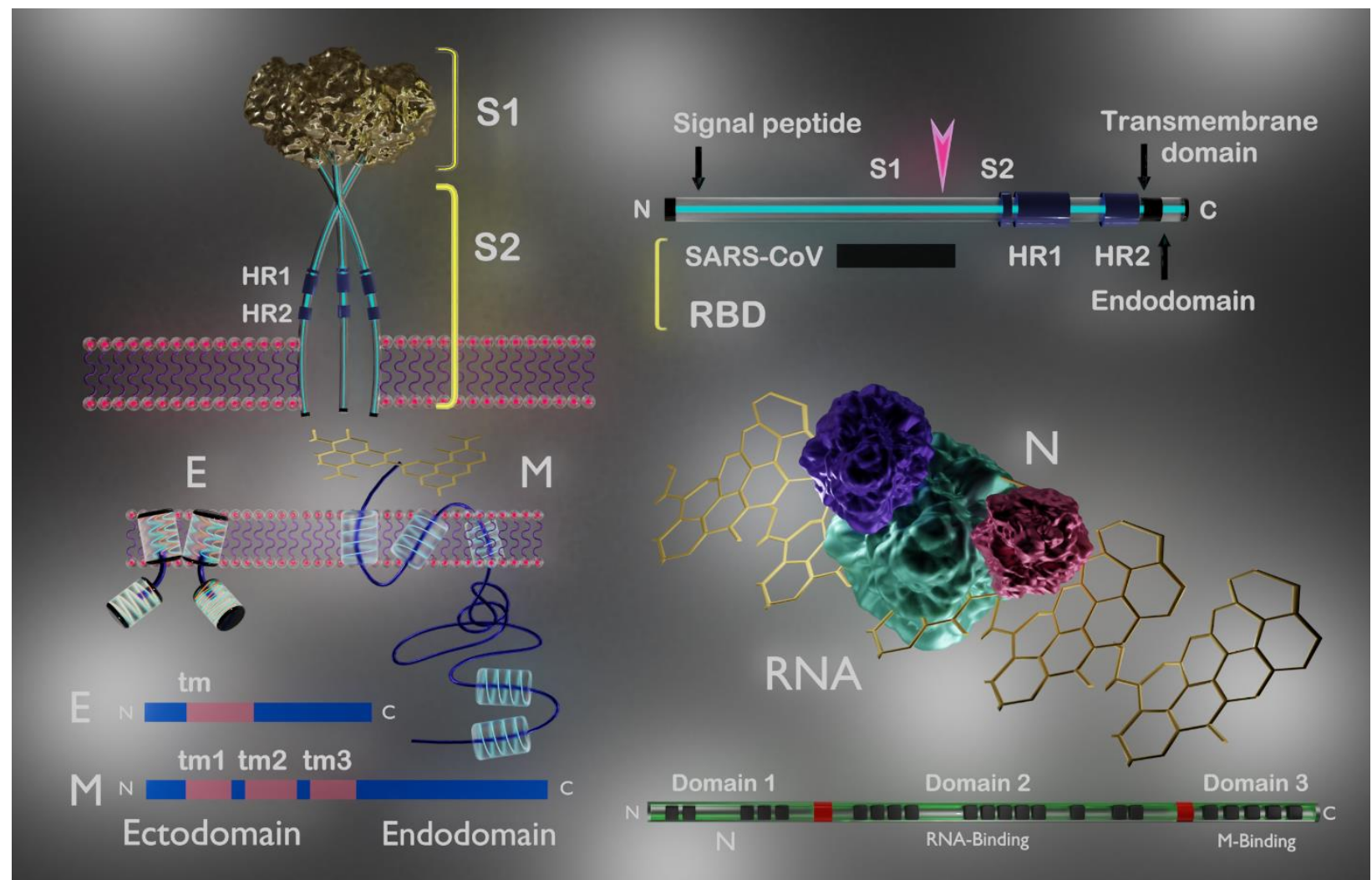

Figure 3 Diagramatic representation of SARS-CoV-2 surface proteins and their replication mechniery, (a) Spike protein molecular and genomic representation, Membrane (M), Envelope (E), Nucleocapsid (N) genomic representation

\section{Transfigurations of the SARS-CoV-2 domain}

In SARS-CoV-2 genome, S-protein is a variable portion consisting of six amino acids receptor-binding domain (RBD), which is a binding site for ACE2. The virus $\mathrm{S} 1$ receptor-binding domain $(\mathrm{RBD})$ plays a key role in the binding of the ACE2 peptidase extracellular domain (PD) in the host. The host proteases cleave the S1-S2 cleavage site and fuse with the host cell membrane (Figure 3 ) (Andersen et al., 2020; Hoffmann et al., 2020; Lai \& Cavanagh, 2006; Stawiski et al., 2020; Belouzard et al., 2009; Simmons et al., 2005). The interaction between RBD and PD was found to be 20 -fold increased affinity, responsible for potential threat for high mortality (Shang et al., 2020; Walls et al., 2020; Wrapp et al., 2020; Yan et al., 2020). However, the phenomena of tropism and transferability were important criteria being analyzed (Walls $\boldsymbol{e t}$ al., 2020).

Exploring the genetic and molecular factors can influence the COVID-19 for aggravating?

The concurrence with the clinical record, genomic expression, and ecological parameters were combined and recognized the impacts in host with COVID-19. Additionally, host genetic parameters are relatively given an idea for the SARSCoV-2 risk factor analysis

\section{ACE variations}

Mysteries are associated with the $\mathrm{CoV}$ genome influences of genetic and molecular factors linked with gene expression. The genetic polymorphism concomitant with tolerance deals with ACE2. The soluble membrane of surface protein contracts with the regulatory mechanism of blood pressure. The ACE2 enzymes play a receptor role for the binding of S protein of SARS-CoV-2 into the human cell surface. Similarly, MERS relatively binds with the dipeptidyl peptidase 4 enzyme expressed from a DPP4 gene integrated with human cells. Researchers are being focused on fining the integrator role of tissue-specific expression of ACE2 variation among individuals under S protein. Procko (2020) identified the polymorphism of ACE2 variants and interface interactions with $\mathrm{S}$ protein via site-directed mutagenesis. The mechanism of viral entry starts with the reorganization of S protein in human ACE2; and initiation of the molecular factors while releasing the RNA genome into the cells via intracellular (Figure 3). Moreover, the development of vaccine and potential therapeutics largely depends on the inhibition of SARS-CoV-2 entry in soluble ACE2. The ACE2 interactions with $\mathrm{S}$ protein induce the host susceptibility being investigated in the human population. Acquired mutations induced by SARS-CoV-2 towards ACE2, producing life-threatening infectious diseases because of the mutation in $\mathrm{S}$ protein augmenting the interface of ACE2. 
b

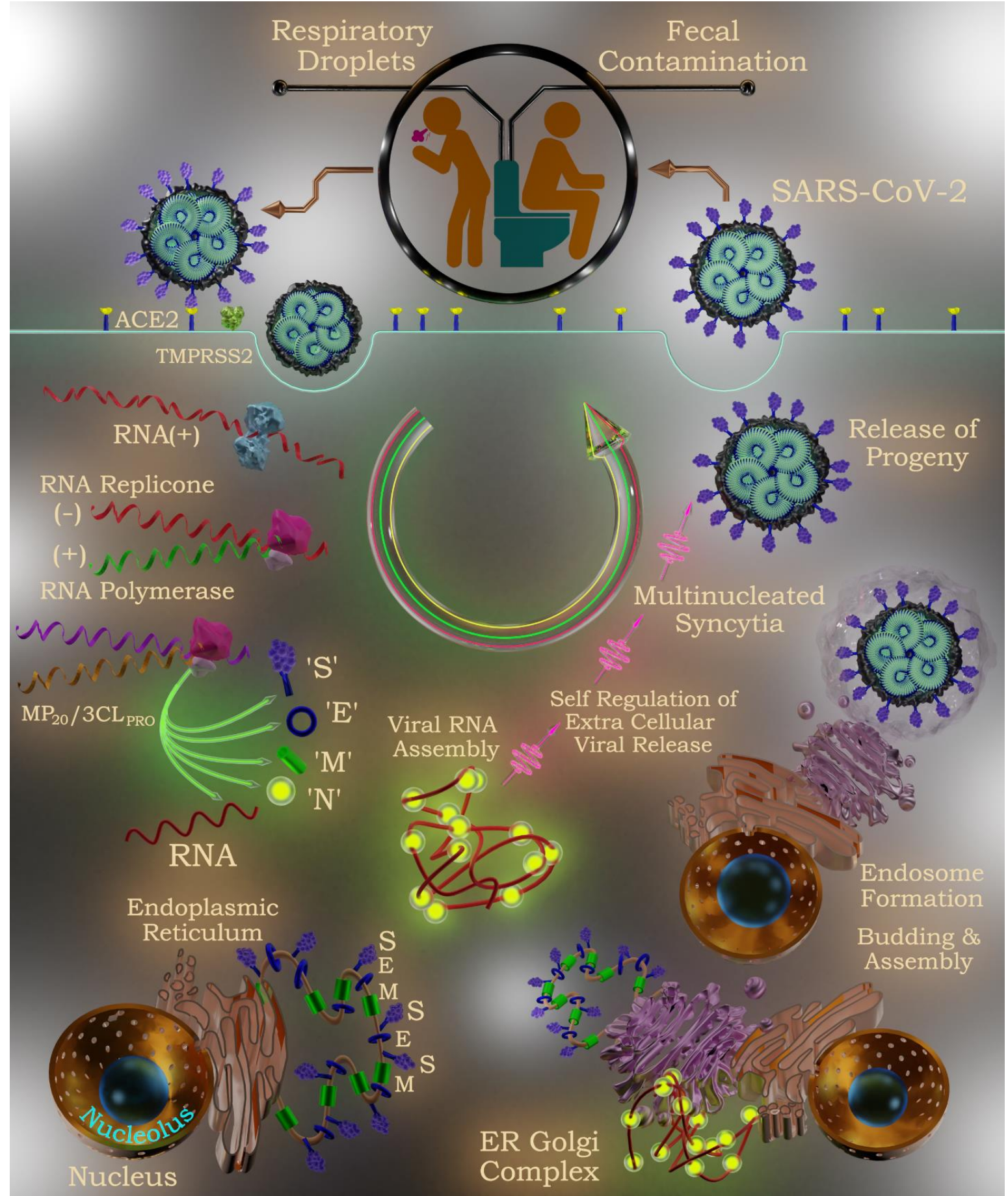

Figure 3 Diagramatic representation of SARS-CoV-2 surface proteins and their replication mechniery. (b) Viral load developmental mechanism of SARS-CoV-2.( Membrane (M), Envelope (E), Nucleocapsid (N) genomic representation).

The polymorphism of the ACE2 receptor predicts the SARS-CoV-2 pandemics, which modify the susceptibility of the CoV genome (Stawiski et al., 2020) (Figure 4). Furthermore, the ACE2 synthetic mutant map was constructed against $S$ protein among a genomic database of 290,000 samples and identified $>400$ population groups. The virus-host interactions, ACE2 diversity linked with the susceptibility of the host. The increased susceptibility was found in ACE2 variants of S19P, 121V, E23K, K26R, T27A, N64K, T92I, Q102P, and H378R. The productive ACE2 variants of K31R, N33I, H34R, E35K, E37K, D38V, Y50F, N51S, M62V, K68E, F72V, Y83H, G326E, G352V, D355N, Q388L, and D509Y have tolerance ability against $S$ protein adherence (Figure 5).

The critical factor of ACE2 variations is determining the resistance and susceptibility of towards viral adherence. The enhanced S-protein RBD affinity in ACE2 mutations is responsible for severe respiratory infections Procko (2020). The compilation of genome-wide variation at the molecular level concluded that the polymorphism of ACE2-PD is a responsible factor for the individual likely to shield or vulnerable to RBD S-protein. Therefore, to design potential therapeutics for preventing the SARS-CoV-2 interactions, it is necessary to sort-out versions of ACE2 that may have a clinical impact (Stawiski et al., 2020). The soluble forms of ACE2-PD proteins that efficiently bind the target of S protein RBD may assist in protecting against SARS-CoV-2.
Moreover, the expression of ACE2 to individual cell types involves several challenges; ACE2 variants deteriorating the coding and non-coding expression part of the gene, tissue types, and the gene expression based on gender. Inversely, the permeation of SARS-CoV-2 is prevented by expression of ACE2 in candidate cell types, which includes nasal olfactory epithelium, tongue keratinocytes, mature enterocytes in the colon, and small intestine. Additionally, the asymptomatic persons possess a forfeiture of sensing is also additional cell types expression causes diarrhea. Furthermore, another interesting fact under manifestation based is the fecal-to-oral transmission of SARS-CoV-2 to susceptible individual cell types. There is lacking knowledge still existing regarding single-cell RNA-seq play a role to determine the cell type's expression, thus essential for qualifying an individual immunity based on SARS-CoV-2. These transcriptomic tools compiling the genomic expression data and quantifiable data of individuals may pave for designing effective therapeutics (Venkatakrishnan et al., 2020).

Additionally, the ACE1-D allele may also involve in the S protein interaction and induces the regional level to increase the mortality rate in ecology (Kenyon, 2020). The expression of ACE1 variance is determined by insertion/deletion (I/D) polymorphism, 65\% DD homozygotes, 31\% ID heterozygotes are present in ACE1. The risk factors of hypertension, cerebrovascular disease, Cardiac arrest, 
hyperglycemia, cancer, respiratory diseases (acute respiratory distress syndrome: ARDS) are associated with D-allele. Therefore, the association of D-allele in SARS-CoV-2 is another key factor for SARS-CoV-2 infection (Gard, 2010;
Deng et al., 2015; Wu \& McGoogan, 2020; Chan et al., 2005; Itoyama et al., 2004).

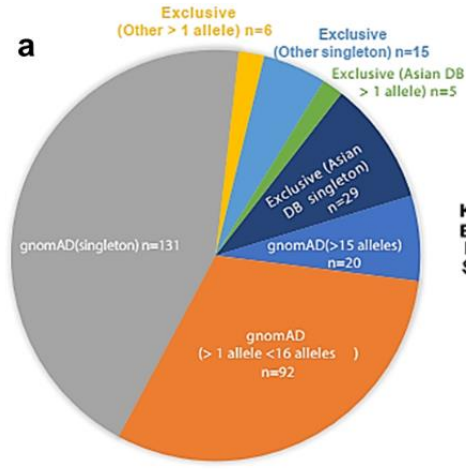

b

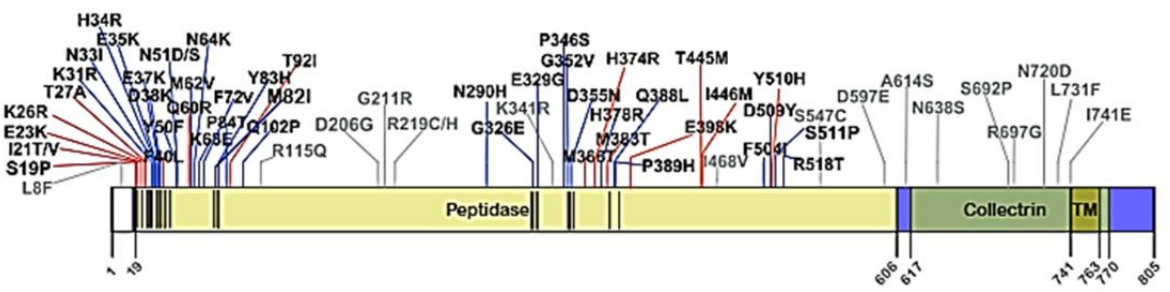

Figure 4 Polymorphisms of ACE2 receptor. (a) Protein mutation in ACE2 variation representation by Pie chart. (b) Polymorphisms of ACE2 protein binding domain (increased red line) to S-protein binding domain (decreased blue line) and the black vertical line represents the interaction of PD-ACE2 with S-protein (Adopted from Stawiski et al., 2020).

a

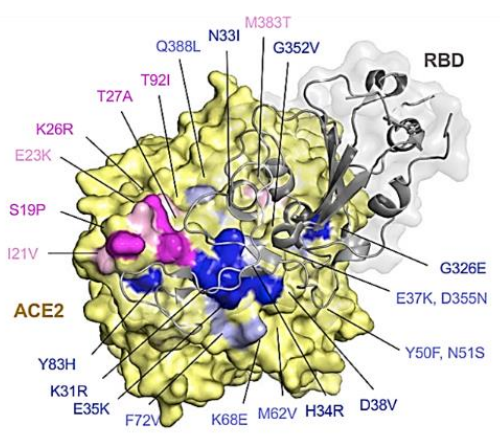

b

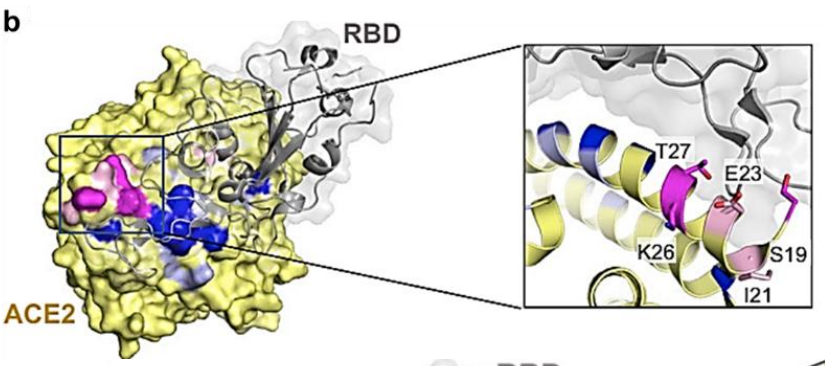

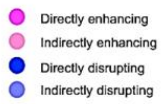

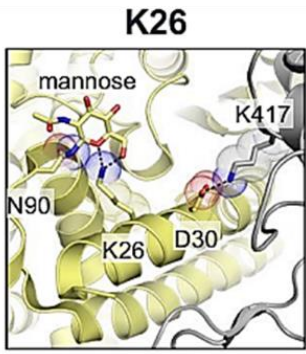

T27

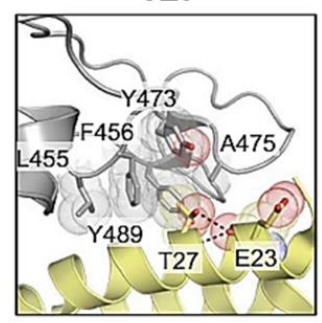

K26R

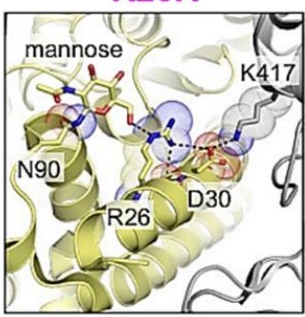

T27A

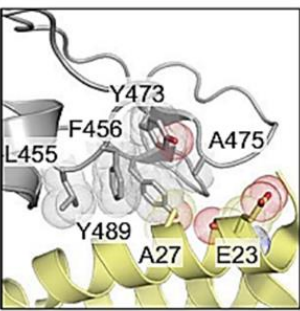

d

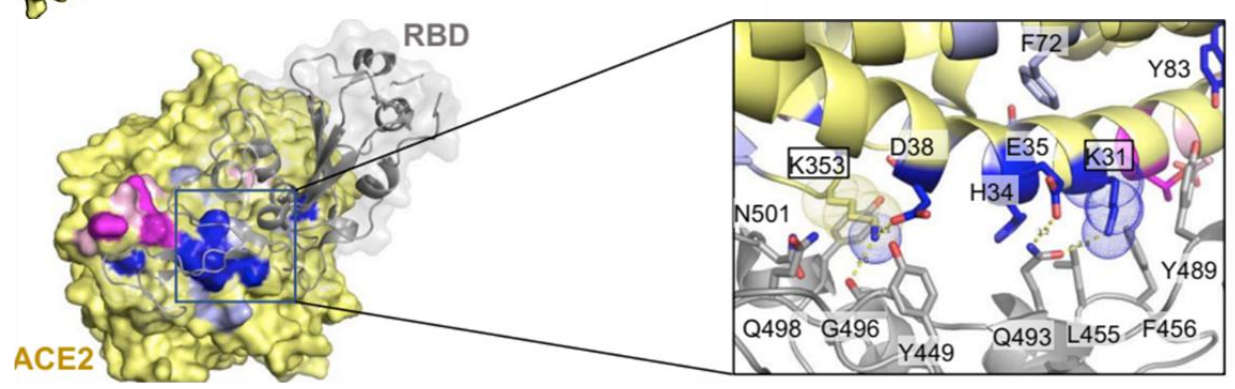

e

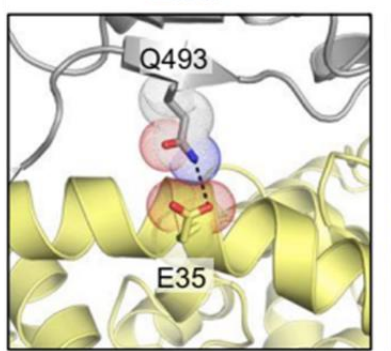

E35K

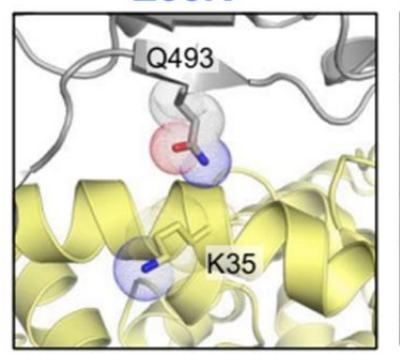

H34

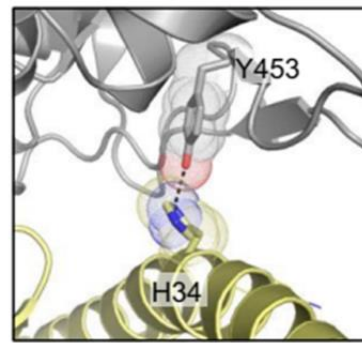

H34R

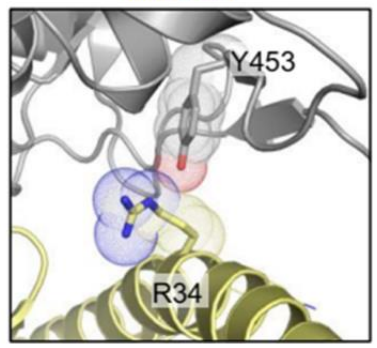

Figure 5 Mapping of ACE2-PD polymorphisms with SARS-CoV-2 RBD. (a) A systematic representation of predicted mutagenesis profile of ACE2 binding with RBD: 6VW1 of S-protein. (b) Structural domain interface interaction between ACE2 with RBD of S-protein. The represented codes are identical as in Figure2b. (c) Recurrent polymorphism region of K26R and T27A. (d) Amino residual of lysine on ACE2 are highlighted in K31 and K353. (e) Polymorphism of ACE2 at E35. (f) Arginine residual mutation of ACE2 H34. PDB of 6VW1 (b, d) and 6LZG (c, e) (Adopted from Stawiski et al., 2020). 


\section{HLA variation}

The genetic architecture of the host genome in response to infectious diseases is associated with the HLA region of an individual, polymorphisms of the protein domain in the epitope of infectious diseases (Tian et al., 2017). Human Leukocyte Antigen (HLA) genes are an alternative determining factor for individual immunity to distinguishing pathogens. The variation of this impact recognizes the foreign viral molecules, such as SARS-CoV-2 induces individual susceptibility towards the virus. Portland VA research foundation, the HLA variation among the individual, could recognize the COVID-19 infection severity from the affected populations. HLA alleles that regulate the prospective epidemiological consequences of SARS-CoV-2 infection. Briefly, the brutality of SARS-CoV-2 is analyzed by a genetic erraticism transversely HLA - A, B, C alleles are class I major histocompatibility complex genes. Additionally, HLA involves the viral recognition pathway; the 145 genotypes of HLA binds with Sprotein were confirmed within silico studies (Figure 6) (Nguyen et al., 2020) The susceptibility of the individual is predicted by the lowest binding peptides of HLA-B (*46:01 exposure) for SARS-CoV-2 (Lin et al., 2003). Inversely, the highly expressed conserved regions of HLA-B (*15:03) genotypes had the greatest resistance to SARS-CoV-2, which facilitates T-cell immunity (Nguyen et al., 2020). Similarly, the significance of HLA genes and their genomic expression additionally links with SARS-CoV-2 host immunity. The border based HLA variation was analyzed with five different populations of 21,546 individuals: Asian, South Asian, European, African, and Latino. The protein expression pattern of HLA allelic variations contributes to the SARS-CoV-2 threat (Nguyen et al., 2020; https://www.covid19hg.org/ (Accessed on 01 May 2020); COVID-19 Host Genetics Initiative, 2020; Godri Pollitt, 2020).

The viral protease of Mpro/3CLpro involved in the central dogma of the viral translation process was reported by Zhang $\boldsymbol{e t}$ al. (2020). The polyproteins of the crystal structure of COVID-19 non-ligand and their potent inhibitor of $\alpha$ ketoamide originated from the inhibitor of the P3-P2 amide bond present in pyridine ring to increase the compound life in plasma was revealed from X-ray structures (Figure 7) (Zhang et al., 2020). Therefore, for designing a vaccine, the inhibitor of $\alpha$-ketoamide is suggested to be an inhalational mode of the administrated drug for lung tropism.

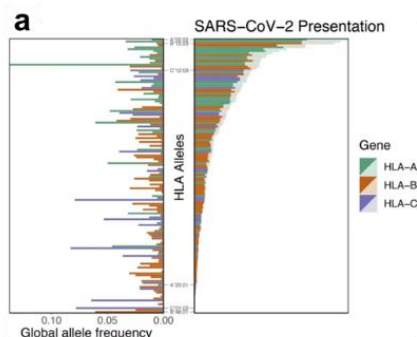

b

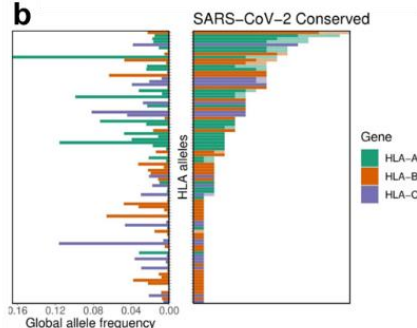

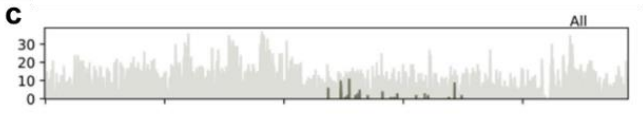
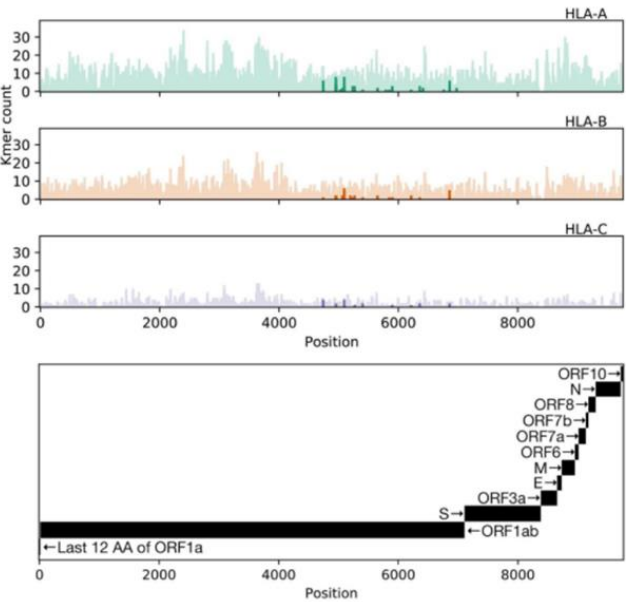

d
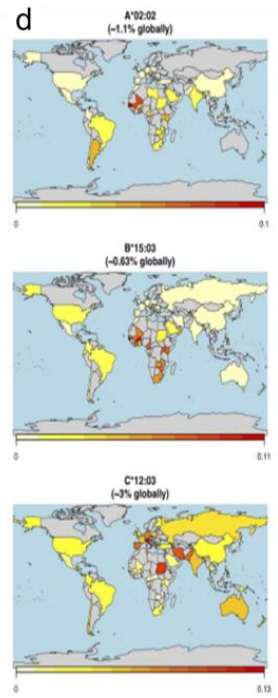
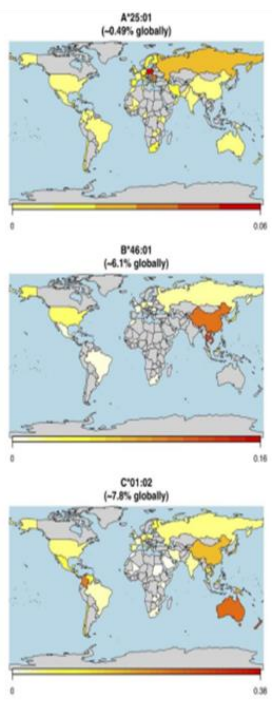

Figure 6 The susceptibility profile of HLA with SARS-CoV-2. (a) Scattering of HLA alleles of 8- to 12-mers from the SARS-CoV-2 proteome. (b) Scattering of HLA alleles highly conserved domains of SARS-CoV-2 peptides with latent to prompt cross-protective immunity. (c) Scattering of HLA allelic conserved 8- to 12mers of general HLA alleles and independently for HLA-A, HLA-B, and HLA-C. (d) Heat maps of six HLA alleles frequency distribution globally (Adopted from Nguyen et al., 2020).

\section{Surface proteins of COVID-19 and host interactions}

The evaluation of spike protein linked vaccines, and antiviral drugs were reported in several studies (Chen et al., 2020; Du et al., 2009). The development of CoV vaccine production is purely dependent on the genome of S-protein, viral cloning vehicle, recombinant DNA, and recombinant S-protein (rS-protein). Besides, the evaluation of drugs activities in the in-vitro and therapeutic analysis is considered the major effectiveness of blockers for SARS-CoV-2; spike protein inhibitors, S1-S2 cleavage site (furin cleavage), ACE2-RBD inhibitors, S-protein-ACE2 fusion core blockers, counteracting antibodies, viral enzymes blockers, Small interfering RNAs activators (siRNAs), recombinant 'interferon's (rIFNs) are major drug designing zone for vaccine research. Noteworthy, the binding domain of RBD of S-protein has strong empathy towards ACE2 (PD) than ACE1, and utility roles have differed. Therefore, the drug designing strategies mainly depends on the ACE2 blockers; e.g., administration of losartan blocks the angiotensin receptor 1 (AT1R). Currently, an Ebola virus drug of Remdesivir pooled with monoclonal antibodies are widely using to treat SARS-CoV-2. However, to determine the frequency of viral mutation and their transformation distribution is a highly challenging task for designing therapeutic drugs and vaccines (Chen et al., 2020; Du et al., 2009; Prabakaran et al., 2004; Gurwitz, 2020; Sheahan et al., 2017; Martinez, 2020).

The surface proteins of S, M, and E of SARS-CoV-2 and their host protein interactions are involved in the maturation of viral protein and assembly into the host cell. The functions of post-translation machinery, mature proteins undergo protein folding and activate as functional proteins; its major functional mediated through glycoprotein maturation, ligand-receptor binding, oligomerization, and functional viral protein activations are the important modifications in host serum In SARS-CoV-2, surface proteins of S, M, and E proliferation, maturation, and subcellular localization with their biochemical properties were discussed in the following sections (Nal et al., 2005).

S-protein relationship in ER (Endoplasmic reticulum) to PM (plasma membrane) of the infected cell

The trimers morphology of S proteins rich in glycosylating, which responsible for the binding of host cell receptors, especially for adhering and transfer of viral genome of SARS-CoV-2 to infect host cell via dendritic cell C-type lectin DCSIGN (Wang et al., 2020; Luo et al., 1999; Delmas et al., 1992; Hofmann et al., 2004; Wang et al., 2004). Briefly, S protein consists of 23 putative Nglycosylation sites, out of 23 putative sites, 12 are enriched with glycosylated (Krokhin et al., 2003; Ying et al., 2004). Also, the S-protein S1 and S2 subunits improved the adherence activity due to the cleavage of MHV (De Haan $\boldsymbol{e t}$ al., 2004). The recombinant His-tagged $S$ - protein-expressing cells consist of $\sim 100$ $\mathrm{kDa}$, represents the $\mathrm{S} 2$ subunit of $\mathrm{S}$-protein (Simmons et al., 2004; Xiao et al., 2004). Moreover, $S$-protein also presents in the endoplasmic reticulum (ER) to the plasma membrane (PM) of the host cell via the secretory pathway (Figure 3 ). The SARS-CoV-2 viral infections are neutralized by anti-S-immunoglobulin may prefer for vaccine development by employing the utilization of a purified form of SARS-S-glycoprotein (Buchholz et al., 2004). 

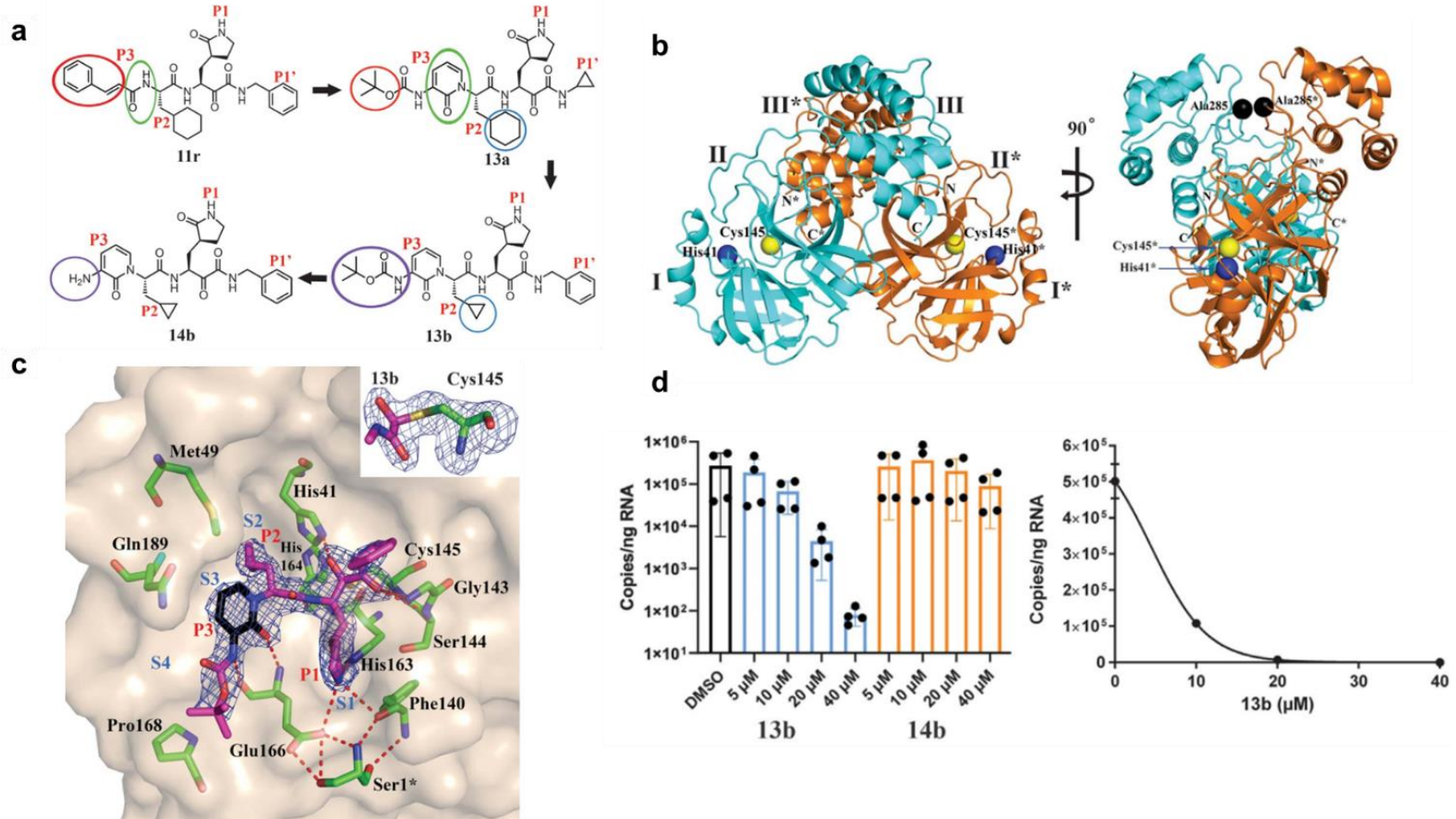

$13 \mathrm{~b}$

$14 \mathrm{~b}$

Figure 7 SARS-CoV-2 Mpro inhibition by $\alpha$-ketoamide. (a) Inhibitors of $\alpha$-ketoamide 11r, 13a, 13b, 14b chemical structure. The oval and circles represents their modifications. (b) The modified forms of Mpro three-dimensional views. Roman numerals indicated the domains. Yellow and blue spheres for catalytic site (Cys145), (His41), respectively. Location of Ala285 indicated by black spheres. N,C terminal for A domain (light blue) and $\mathrm{N}^{*}$ and $\mathrm{C}^{*}$ for protomer B (orange). (c) SARS-CoV2 Mpro monoclinic crystal form binding with $13 \mathrm{~b}$ compound of $\alpha$-ketoamide. (d) the confirmatory study of $13 \mathrm{~b} \alpha$-ketoamide inhibitor role in COVID-19 infected human Calu-3 lung cells (Adopted from Zhang et al., 2020).

\section{M-protein interactions with ER and Golgi of the infected host cell}

The surface of the viral structural protein is enriched with $\mathrm{M}$ protein in mammalian cells, which is N-but not O-glycosylated. The leukocytes production is induced by interferon (IFN), which is stimulated by M-glycoprotein. However this activity is influenced by the interferometric activity of the glycosylation status of M and N (De Haan et al., 2003; Baudoux et al., 1998). The infected host cell Golgi apparatus (GA) is highly concentrated with surface proteins of $\mathrm{M}$. However, M-protein distribution differs from viral strains (Krijnse-Locker et al., 1995; Neuman et al., 2016). In addition, SARS-CoV-2 of M glycoprotein localizes with ER, endoplasmic reticulum-Golgi intermediate compartment (ERGIC), and cis-Golgi (Figure 3) (Nal et al., 2005; Appenzeller et al., 1999). Although, the expression of M-protein is not detected at the plasma membrane, which was accumulated and transported from the Golgi apparatus to Endoplasmic Reticulum.

\section{Envelope protein assembly in the host cell}

The viral assembly and accumulated of $\mathrm{CoV}$ at the minimum level in the viral envelope region are carried out by E-protein (Corse \& Machamer, 2002; Lim \& Liu, 2001). Although, E protein is co-expressed with M-protein for assembly of viral protein and expressed in a stable condition when combined with tiny envelope glycoprotein (Vennema et al., 1996; Raamsman et al., 2000) However, individual expression of E-protein lifetime is only $30 \mathrm{~min}$. Therefore, the viability of E-protein regulation that occurred at post-translation events was reported by (Nal et al., 2005) (Figure 8). Additionally, the E-protein degradation phenomenon corresponds to the palmitoylated mediated regulation process, in which three cysteine residues were deducted in juxta membrane (Corse \& Machamer, 2002; Arbely et al., 2004). The bend membranes structures are in the form of the tubule and smooth is transported from ERGIC (Endoplasmic reticulum Golgi complex) to ER

The SARS-CoV-2 grows from the subcellular localization of ERGIC (Nal et al., 2005). The post-entry is present into the inside of ER and was present for 30mins, in Golgi, the high-mannosylated S, M proteins are assembled in the order of trimers with adherence of $\mathrm{N}$-glycans. Although $\mathrm{M}$ localized in Golgi whereas $\mathrm{S}$ is sub-localized in ER to PM with a secretory pathway. The remaining nonglycosylated of surface envelope protein $\mathrm{E}$ localize at perinuclear patches with ER. Therefore, the differential variation in subcellular localization of surface proteins might be expressed along with factors associated with cellular and viral components, which is necessary for the transport of assembled budding viruses into the ERGIC (Nal et al., 2005) (Figure 3; Figure 8). However, the surface proteins biogenesis, variance of maturation, regulations of viral protein assembly with their host cell partner is still under at budding stage (Fischer et al., 2007). a

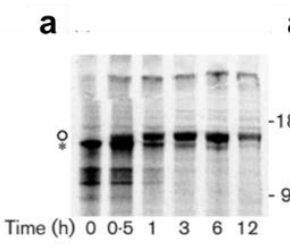

a1

EndoH

a2

b
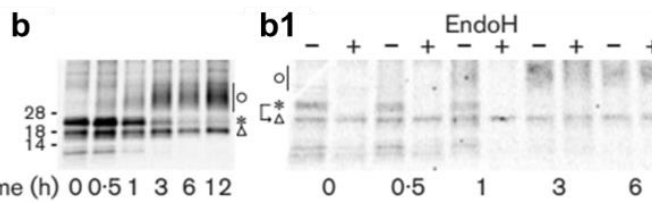

C

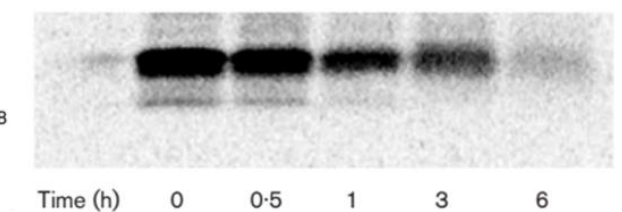

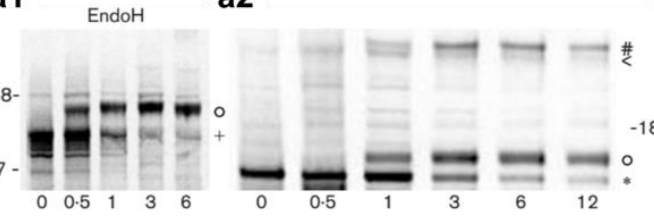

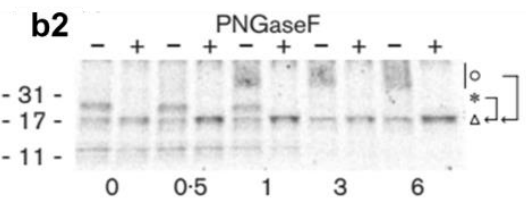

Figure 8 (a) SARS-CoV-2 surface S-protein interactions with host cell (BHK-21). (a1) SARS-S protein interactions from 0 to 12h. (a2)SARS-S treated to EndoH treatment. (a3) Better separation of S-protein bands for longer durations onto a SDS-PAGE, (*) Endoglycosiase - (EndoH); (O) EndoH-resistant S glycoform represented in 180KDa; (+)150KDa EnoH-processed S glycoform;EndoH-sensitive trimer (<); EndoH-resistant S trimer (\#). (b) EndoH- resistant complex glycoform of N-glycosylated SARS-M protein and their maturity upto 0-12h on BHK2. (b1) SARS-M protein interactions from 0 to 12h. (b2) SARS-M treated to EndoH treatment (+, exposed), (-,non-exposed) to PNGaseF (peptide-N-glycosiase F). (b3) ( $\Delta$ ) Non-glycosylated of M; (*) sensitie M-glycoform of EndoH and PNGaseF; (O) M-glycoform of EndoH-resistant and sensitive PNGaseF. (c) Degraded E-protein of SARS-CoV-2 from 0-6h (Adopted from Nal et al., 2005) 


\section{POST COVID-19 AND OTHER DISEASE MANIFESTATIONS}

Currently, there is an uncertain dispute about whether SARS-CoV-2 induces acquired immunity after SARS-CoV-2 infection? However, the respiratory infection of influenza and related viral pathogens in humans 'doesn't contribute to increasing immunity. Although the potential impact of post-infection immunity is to participate in the major consideration for the determination of individual immunity. The respiratory syndrome of SARS-CoV-2 infection increases the IgM and $\mathrm{IgG}$ antibodies in host immunity in severely infected hosts (Zhao et al., 2020; Wolfel et al., 2020; To et al., 2020). Besides, the antibodies evaluation in the host humoral system during post-SARS-CoV-2 infection was not detecting an anti-immunoglobulins in individual sera. The association between antibody titers and clinical applications is still unclear. Furthermore, the $\operatorname{IgM}$ and $\operatorname{IgG}$ antibodies were increased during higher viral loads of COVID-19.

The viral load is typically higher in early infectious status and declined in when antibody titers develop probably within 3 weeks. However, the presence of the SARS-CoV-2 genome at higher concentrations without the release of symptoms is detected in post-SARS-CoV-2 individuals and acts as non-transmitters (Wölfel et al., 2020). Even though a clear sign of the presence of viral load in host sera during the post-SARS-CoV-2 infection is uncertain. However, the presence of neutralizing antibodies in individual sera is persistent for more than a month Especially, the concentration of $\mathrm{IgG}$ is higher half of the year (Wu et al., 2007). Similarly, MERS- CoV neutralizing antibodies persisted until 34 months in postMERS-CoV individuals (Payne et al., 2016; Bao et al., 2020). Cavanagh et al. (2004) reported that the respiratory illnesses caused by the other four human coronaviruses of 229E, NL63, and OC43 were developed during re-infection; the protective immunity lived for the minimum period in infected persons, and also the post-exposed strains were genetically identical.

Up to date, there is no evidence of reported cases of re-infected SARS-CoV-2 Although, the culturing of the re-infected individual host has not shown distinct results. A recent report state that the recovered SARS-CoV-2 healthy individual samples of polymerase chain reaction (PCR) indicate the negative, which was collected from the upper respiratory tract of the individual after $24 \mathrm{~h}$. Similarly, the genome was collected in throat swabs and nasopharyngeal swabs for 20 days after discharge of SARS-CoV-2 patients, although the test results are negative
(Xiao et al., 2020). Additionally, the post recovered patients were radiographically inspected, and the results show a stable improvement (Xing $\boldsymbol{e t}$ al., 2020; Young et al., 2020). Moreover, the transmission of SARS-CoV-2 in post carrier is not clinically proven yet (Kirkcaldy $\boldsymbol{e t}$ al., 2020).

Xing et al. (2020) reported, among 62 medical supervisors were affected by SARS-CoV-2 and recovered in Zhongnan Hospital in Wuhan, China. The postrecovery surveillance of two asymptomatic cases shown swabs test are positive and the disease manifestations are shown mild symptoms. It confers that a small fraction of discharged patients might test positive and they are non-transmitters A minimum quantity of SARS-CoV-2 symptoms from recovered patients is difficult to isolate and detect the virus proposition. The current detection tool of RT-PCR, sensing 97\% of accuracy, even though the remaining 3\% diagnostic specificity is showed false-positive because of random sample analysis (or) specificity of sample collection and methods of sample processing durations (Xie et al., 2020). Besides, after recovery from SARS-CoV-2, the host body requires some duration to eliminate the viruses from their immune system (Shen et al., 2020). Moreover, it may combine with the host immune system and exhibit as positive and the clinical manifestations of asymptomatic "patient's chest CT showed no evidence of virus survival. However, in some cases reported in Hunan Province, China the post- SARS-CoV-2 patient exhibit cough and fever for 2 days after discharge from hospital, and the disease manifestations showed deteriorated grade of the chest while CT investigation, it might be the decline of patient immune power (Xing et al., 2020; National Health Commission of Changde, 2020) (Figure 9). Even though, at present, it is highly critical to find a clear justification for the above manifestations. Also, some clinical implications of SARS-CoV-2 have some clear clarification regarding the false-positive. It was presumed that the viral location at the initial stage could detect easily at the upper respiratory tract. Moreover, the proliferation and maturation of viral detection appear likely in the lower respiratory tract, intestines, and blood (Zhang $\boldsymbol{e t}$ al., 2020). In such cases, the detection of viruses in the swab test showed negative. Therefore, it may elucidate false-negative at the preliminary stage of qRT-PCR but positive in manifestations of CT-chest (Xie et al., 2020; Fang et al., 2020). a

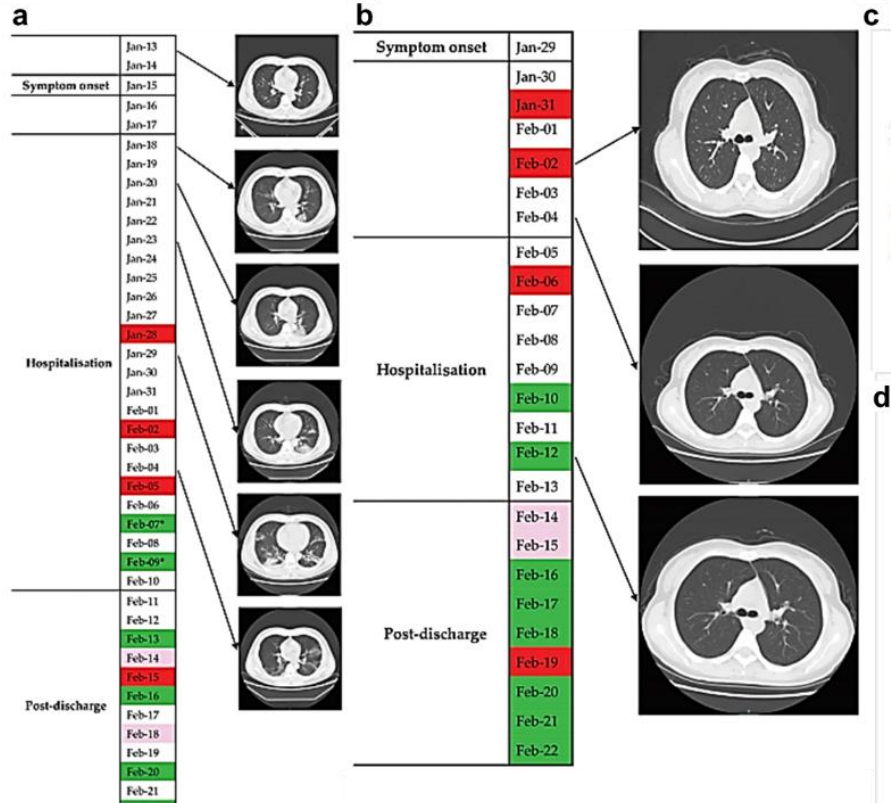

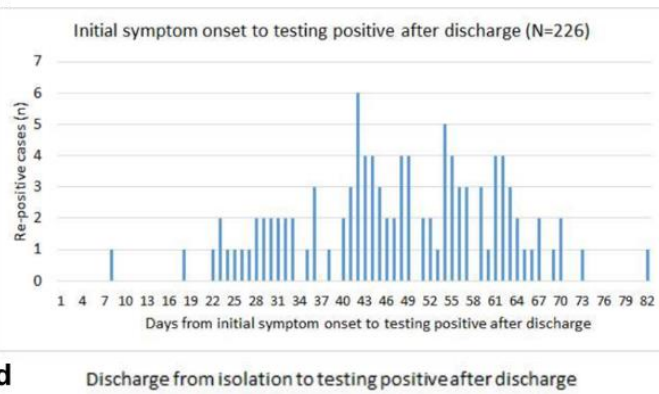

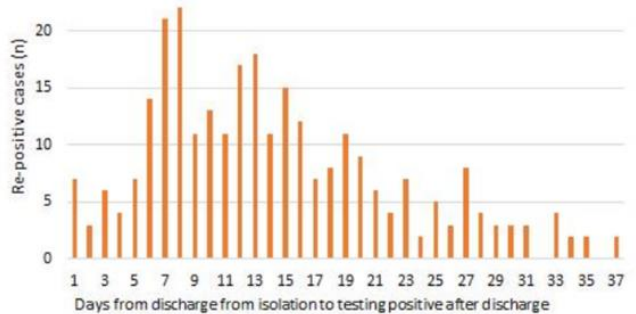

Figure 9 COVID-19 post-discharge surveillance and re-infection status of two medical staff's case history profiles from January to February and re-infected cases investigation profiles of KCDC. (a) Case 1 details of throat swab virus detection and chest-CT, Critical status of Chest reflected in CT scan shown worse morphology of SARS-CoV-2 viruses' detection on $18,20,23$ and $29^{\text {th }}$ January and followed by improved status on $4^{\text {th }}$ February. (b) Case 2 , throat swab test and CTscan details of chest shown normal views on 2,4 , and $12^{\text {th }}$ February. (On throat swab test colour indication denotes; red: Positive virus presence; pink: faintly positive; green: negative virus detection; asterisk: negative virus detection in stool) (Adopted from Xing et al., 2020). (c) KCDC- discharged cases re-positive initial symptomatic average of 44.9 days from 226 cases in the range of 8-82 days from primary symptom commencement date. (d) Discharged positive cases on bases on 285 cases in the range of 1-37 days (Adopted from KCDC, 2020).

The epidemiological analysis and communication examination of re-infected cases of 285 patients were identified out of 447 patients and a sum of 790 peoples have contacted members of 285 re-infected peoples, out of them the 351 members are closely related to family members and remaining 439 members are non-related, reported by KCDC-2020 on 15 ${ }^{\text {th }}$ May 2020 (Korea Centers for Disease Control \& Prevention, 2020). From this above investigation, there have been no cases reported as positive from re-infective carriers even though they have coughs, sore throat, etc (Korea Centers for Disease Control \& Prevention, 2020) (Figure 9). Experimental evidence from Bao et al., (2020) showed the re-challenged Rhesus macaques with SARS-CoV-2; an initial recovery stage from the early stage of infection was evaluated by loss of weight, viral propagation, and respiratory diseases in pneumonia were identified in the lungs and intestine. Furthermore, the re-exposure of infection not produce viral colonies was evaluated from the clinical manifestations and host-pathogen studies. The presence of neutralizing antibodies present in the Rhesus monkeys might be the reason for viral protection in their body (Bao et al., 2020; Yu et al. 2020). Therefore, SARS-CoV-2 induces immunity in the host system and protects the host from subsequent re-infection (Figure 10 \& 11) (Bao et al., 2020). 
It is highly difficult to evaluate the frequency of SARS-CoV-2 infections, even in asymptomatic via serological assays. However, the individual re-infection determination at an early stage is also essential for the COVID-19 assessment Although, the specificity, sensitivity and cross-reaction latent is also be required factor for SARS-CoV-2 determination (Kirkcaldy et al., 2020). The COVID-19 recovered individual's population and a healthy population of the non-affected individual population may produce false-positives. Therefore, the above issues are highly complicated to correlate the medical and epidemiologic analysis with serological results. Furthermore, the dispute between the releases of $\operatorname{IgG}, \operatorname{IgM}$ 'immunoglobulin's under SARS-CoV-2 and posts SARS-CoV-2 infections (Bao et al., 2020). However, inadequate supporting data are available for $\operatorname{IgG}, \operatorname{IgM}$ 'immunoglobulin's production against SARS-CoV-2, and post-COVID potential to confer resistance for re-infection (Kirkcaldy et al., 2020). Therefore, it is necessary to evaluate the phenomenon of post-SARS-CoV-2 immune responses is highly required for further investigation to prevent viral transmission and which may help to save public health in a current scenario.

\section{Comorbidities of COVID-19 positive during pregnancy}

The pregnant ladies are in a highly risky zoon for SARS-CoV-2 infection: which causes health defects in both maternal and neonatal (Liu et al., 2020). A sum of 13 Chinese pregnant ladies was infected with SARS-CoV-2; the maternal age of between 22 to 36 years was admitted to the hospital in Wuhan, China, on 8th December, 2019. The gestation period of two women is below 28 weeks, and others are below third trimesters. All of them are healthy other than SARS-CoV2 complications. Their body temperature range between $37.3-39.0^{\circ} \mathrm{C}$, the symptoms like fever with fatigue was observed in ten maternal along with three of them noted like dyspnea. The epidemiologic history of 12 members had close contact with infected peoples. Out of 13 maternal, three of them are improved their health conditions and discharged. From the remaining 10 maternal, five of them are undergone emergency cesarean because of fetal distress (in three), premature rupture of uterus membrane (in one), dead of the fetus (in one). During the hospitalization of the $6^{\text {th }}$ patient condition worsened, she was suffered from multiple organ dysfunction syndromes (MODS), acute respiratory distress syndrome (ARDS), acute hepatic, and renal dysfunction with septic shock. Hence the patient was provoking to the intensive care unit (ICU) with ventilator support. The remaining 12 patients were discharged healthy without any clinical complications on $25^{\text {th }}$ February, 2020. Therefore, an investigation of the above case history proven the completions of SARS-CoV-2 increased the susceptibility of infection in both maternal as well as fetus health. Furthermore, severely complicated patents had a cytokine storm because of the maximum production of plasma induces the hyperactivity of various cytokines (Huang et al., 2020). The most complicated three of them had dyspnea; it may due to the late pregnancy causes hypoxia during viral infections to promote maternal distress (Assiri et al., 2016). However, these viral complications may not affect the fetus asphyxia except abortion (in one) (Liu et al., 2020).

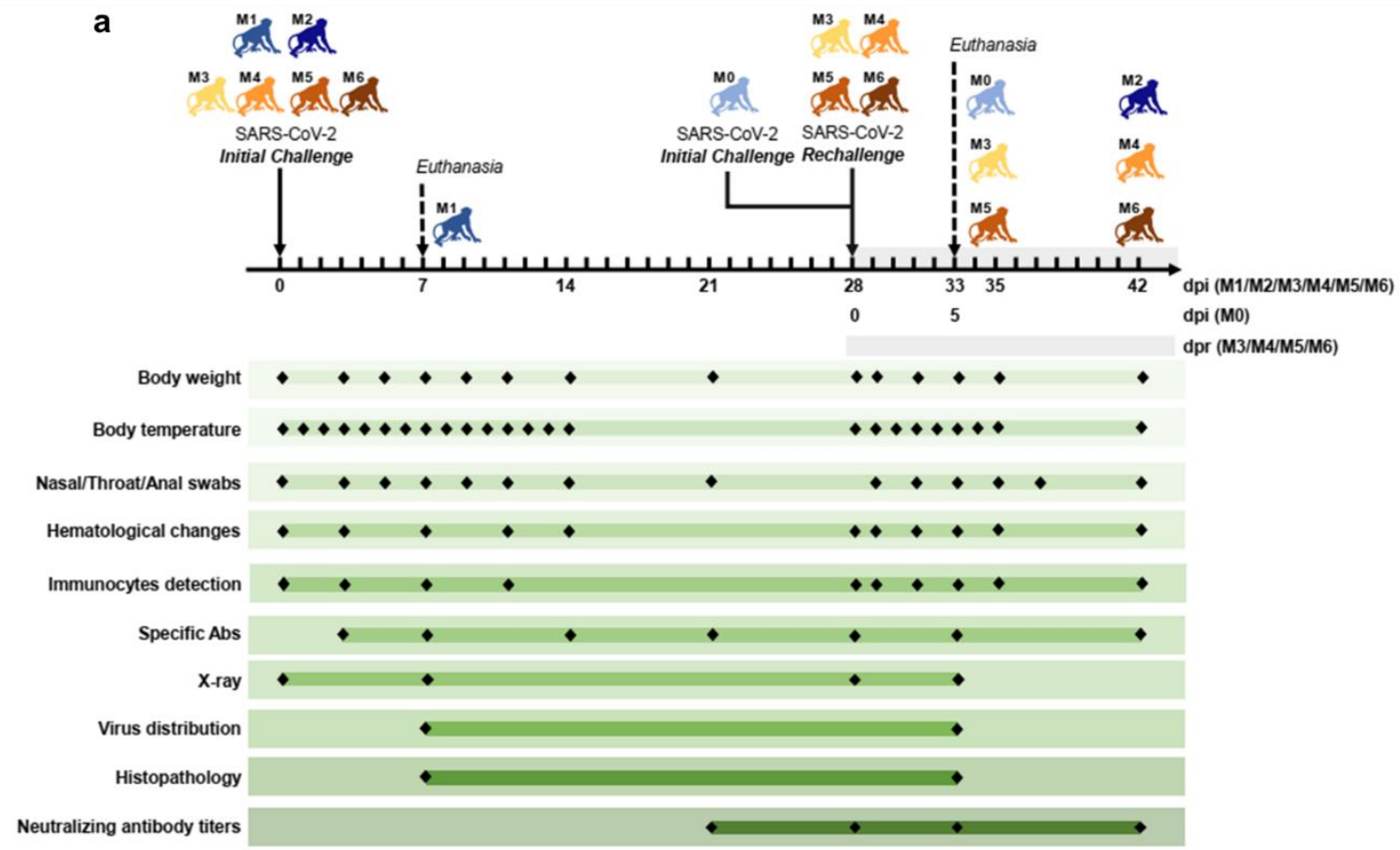

Figure 10 Investigation of prolonged infectious status of early SARS-CoV-2 infection and re-infection tracks identified in Rhesus macaques. (a) Chinese-origin of six rhesus monkeys were selected (3-5kg, 3-5 years old), labelled M0-M6 and modeled for early and late infection of SARS-CoV-2 via intratracheally $\left(1 \times 10^{6}\right)$ surveillance (Adopted from Bao et al., 2020).

\section{Pathophysiology of COVID-19 with an acute kidney infection (AKI)}

Remarkably, the transcriptome studies reveal that the degree of kidney cells in ACE2 expression ligand with SARS-CoV-2 receptors and TMPRSS proteases association were identified and the mechanism of infection in kidney cells was diagnosed. The expression of kidney regulation genome function was higher in western contributors than Asian donors. Furthermore, it's suggested that occidental donors are more susceptible to SARS-CoV-2 infection, especially in renal failure fairly than Asian origin (Batlle et al., 2020; Pan et al., 2020) Significance observation reported in medRxiv, among 85 patients $23 \%$ is the prevalence of AKI. Epidemiology of renal failure from post-mortems reports declares that the occurrences of severe acute tubular necrosis (SATN) consist of lymphocyte and macrophages accumulation on their kidney region (Diao et al., 2020). Another autopsy investigation of COVID-19 patients showed acute proximal tubular damage with erythrocyte clumping and glomerular fibrin thrombi (Su et al., 2020). Remarkably, SARS-CoV-2 impacts in China and the United States endorsed that aggregation of clotting factors, scattered intravascular coagulation, tiny vessel thrombosis with a respiratory infraction were noted on autopsy reports. In some cases, additionally exhibits low platelet counts were found in autopsy patients (Tang et al., 2020; Zhou et al., 2020). Furthermore, Zhou et al. (2020) the manifestations of SARS-CoV-2 substantiation of myocarditis and microangiopathy in multiple organs, such as splenic infarction, hematuria, myocardial infraction initiates to cortical necrosis and renal failure.

\section{Mechanism of SARS-CoV-2 on Kidney infection}

Notably, the genome of SARS-CoV-2 not present in the kidney of infected persons, although it is believed that the SARS-CoV-2 might affect directly to the renal tubules and causes inclusions in renal tubules, nephropathies. Although, the feature aspect of SARS-CoV-2 infection, the genome of SARS-CoV-2 recognizes the ACE2 receptors in the kidney rather than in the lungs (Batlle $\boldsymbol{e t}$ al., 2020; Serfozo et al., 2020; Ye et al., 2006). The expression of ACE2 is originated in the proximal tubule of the brush border apical membrane surface, where it recognizes the ACE enzyme. The invading viruses adhere to podocytes and utilize the tubular fluid machinery, followed by binding with a proximal tubule. Moreover, the ACE2 expression is present in the apical surface of epithelia in humans; however, the occurrences of infection are noted on the basolateral membrane with minimal potency (Jia et al., 2005). Additionally, SARS-CoV-2 infection is also associated with the proteases in host cells; TMPRSS2 is expressed initially in distal nephron (Batlle et al., 2020; Wu et al., 2018; Wilson et al., 2019). Although the biogenesis of viral manifestation is initiated by $\mathrm{S}$ protein furin cleavage (Walls et al., 2020). The additional manifestations of AKI with SARS-CoV-2 infection are caused by proteinuria, excessive hemophagocytic macrophage stimulation, microangiopathy, and glomerulopathy. 
In addition, the level of ACE2 is downregulated during AKI, which leads to activation of the ACE enzyme with low angiotensin accumulation causes of AKI damage (Su et al., 2020; Bhatraju et al., 2020). Moreover, the higher risk factor linked with AKI is diabetic kidney disease (DKD) due to the up-regulation of $\mathrm{ACE}$ as well as ACE2 down-regulations.
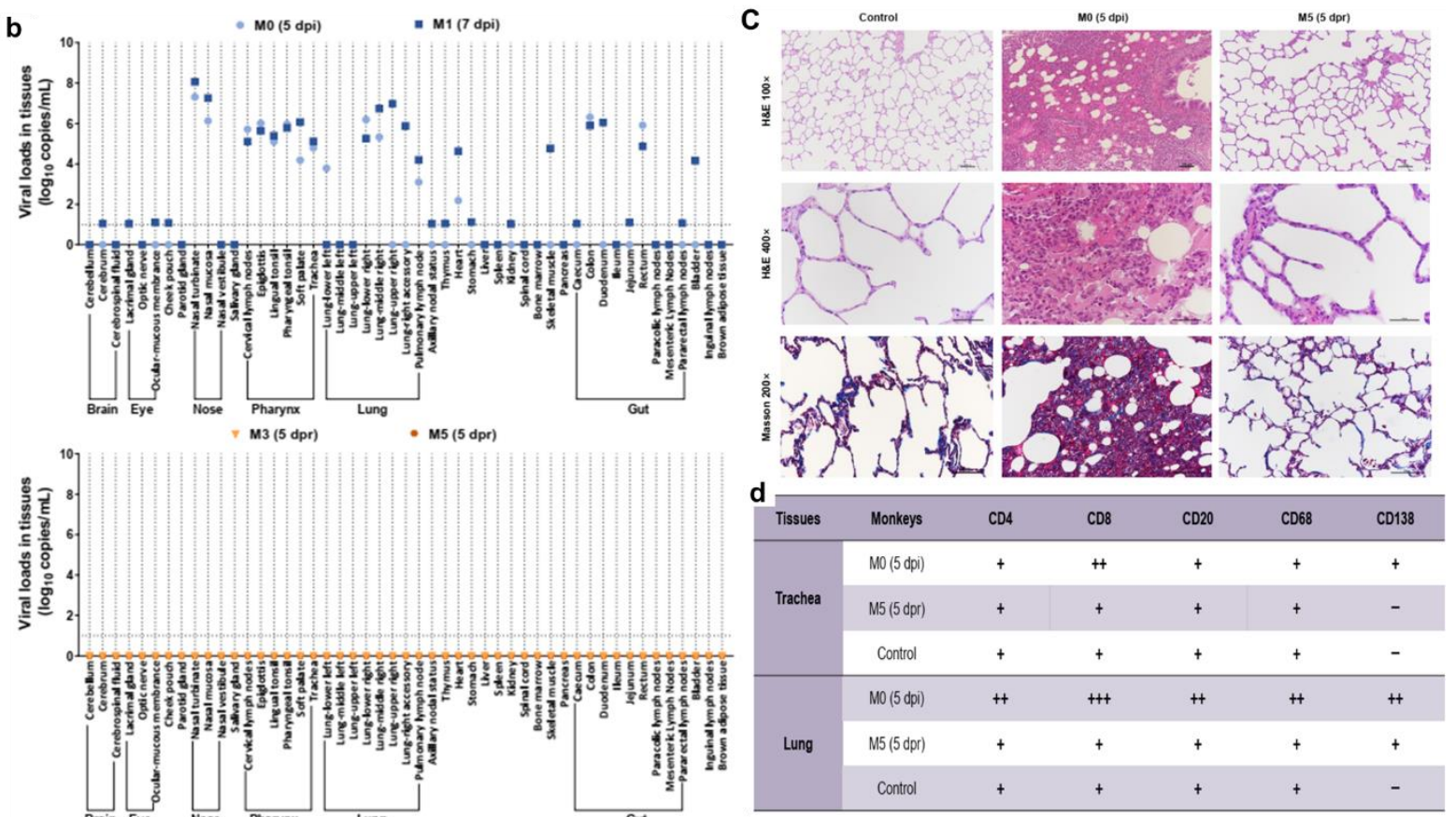

Figure 11 Investigation of prolonged infectious status of early SARS-CoV-2 infection and re-infection tracks identified in Rhesus macaques. (b) Detection of viral RNA in internal organs of M0 and M1 were early infected with SARS-CoV-2 and re-challenged profiles of M3 and M5. (c) Histopathology studies of M0 and M5 shown that the re-challenged rhesus viral load. (d) The evaluation and score details under immunohistochemistry (IHC) of CD4, CD8 for T cell, CD20 for B cell, CD68 for macrophage and CD138 for plasma cells (Adopted from Bao et al., 2020).

\section{Manifestations of SARS-CoV-2 on acute cardiovascular disease (ACV)}

Understanding the phenomenon between SARS-CoV-2 with cardiovascular $(\mathrm{CV})$ and acute cardiovascular $(\mathrm{ACV})$ is an additional requirement for disease management. The clinical manifestation of SARS-CoV-2 causes pulmonary infections, although the CV illness is not much more common. The cardiac illness is measured by increasing the troponins in the cardiac region leads to ACV; almost $8-12 \%$ of people are affected with ACV. The mechanism of cardiac damage occurred due to viral attachment in cardiomyocytes and caused systemic inflammation (Bansal, 2020). Moreover, direct myocardial infection, transformed myocardial demand, plaque rupture, coronary thrombosis, imbalances of electrolyte, antagonistic effects of various drugs are risk complications associated with SARS-CoV-2 (Bansal, 2020).

Acute myocardial damage (ACD) is one of the commonly found complications associated with SARS-CoV-2 infection. The rising of the cardiac enzyme of troponin I (cTnI) has one of the reference markers to identify the ACD (Zhou $\boldsymbol{e}$ al., 2020; Lippi \& Plebani, 2020). The comparative role of viral myocarditis and systemic inflammation induces the direct myocardial injury. The pandemic outbreak of SARS-CoV-2 in Toronto has confirmed the observations as mentioned earlier in autopsy patients (Oudit et al., 2009); 35\% of the viral genome was found in autopsy patients of heart samples. Similarly, Zhou et al. (2020) observe the SARS-CoV-2 complications with ACD is minimum percentage compared to recovered patients (12\%). In addition to the cTnI, other biomarkers of the brain-type natriuretic peptide, arrhythmias, myocardia infarction, and heart failure are likely to be used to access the ACD (Akhmerov \& Marbán, 2020). However, the markers, as mentioned above, the detailed mechanism of ST-segmental myocardial infarction, left ventricular systolic dysfunction, acute left ventricular failure, and acute cardiac shock has not been reported elsewhere (Bansal, 2020).

\section{COVID-19 interactions in the respiratory tract}

The infection status from pre-symptomatic (first 3 days) to post-symptomatic ( 8 weeks) via early symptomatic stage (4 weeks), hence the incubation period is signified as 14-28 days. The lower respiratory tract as a moderate infection center for SARS-CoV-2. Noteworthy, the higher viral load is defecated by an asymptomatic patient (Vardhana \& Wolchok, 2020). The S-protein binding in the ACE2 cell surface receptors regulates the renin-angiotensin-aldosterone system (RAAS), which function as regulations of blood-pressure, vasoconstriction, vasodilation (Hoffmann et al., 2020), Furthermore, the expression of ACE2 in mucosal epithelium covered by the nasal, nasal cavity, and lung infection mediates the respiratory tract infection. In addition, the expression of ACE2 also been found in the endothelium, cardiac, gut lineages, and renal tubes spread the viral load unconditionally (Subbarao \& Mahanty, 2020).

Moreover, the post- SARS-CoV-2 induces the release excess of cytokine secretion. The infection in the lung epithelial cells stimulates the monocytes macrophages, interleukin-6 (IL-6), dendritic cells to secrete vast proinflammatory cytokines. The release of IL-6 initiates the proliferation and differentiation of lymphocytes regulation in T-helper cells $\left(\mathrm{T}_{\mathrm{H}} 17\right)$. Consequently, IL-6 stimulates the release excess of immune cells, which results in cytokine storm, which initiates blood pressure deviation, acute respiratory distress syndrome (ARDS). Therefore, to suppress the hyperactivity of immune cell secretion due to IL-6 in SARS-CoV-2 necessary, currently, immunosuppressive drugs, such as Tocilizumab, Siltuximab, and Sarilumab are clinically used for treating infected patients (Moore \& June, 2020). Additionally, the amplified production of cytokines induces the massive secretion of fibrinogen and coagulation pathways on surfaces of endothelial cells, which is confirmed by the presence of D-dimer released from a fibrin cleavage. Moreover, the RAAS additionally prompts blood vessels shrinking and dyspnea. Similarly, the event was reported SARS-pneumonia tempts to reduce the oxygen supply in blood vessels but does not dyspnea (Subbarao \& Mahanty, 2020). SARS-CoV-2 induces the obstruction of oxygen uptake due to the clogging of blood vessels in pulmonary tracts leads to the accumulation of coagulated small blood vessels induces severe dyspnea. Henceforth, for the treatment of severe dyspnea, anticoagulants, such as Coumadin, Xarelto, Eliquis, Pradaxa, and Savaysa, are highly recommended in SARS-CoV-2 patients (Subbarao \& Mahanty, 2020).

\section{COVID-19 manifestations in Liver}

Viral infection in liver cells directly causes impairment of the liver organ Notably, 2-10\% of infected patients had liver damage causes diarrhea and diagnosed with the presence of viral RNA in their stool and blood specimens (Yeo et al., 2020). However, the absence of viral inclusions in liver tissue displays a lower titer value after the histopathological studies (Zhang $\boldsymbol{e t}$ al., 2020). Liver biomarker of gamma-glutamyl transferase (GGT), alkaline phosphatase used to estimate the expression of ACE2, and it is higher in cholangiocytes to find the regulation of liver activity (Chai et $\boldsymbol{a l}$., 2020). The autopsy investigation of SARS-CoV-2 patient's proven the non-exhibit the viral load in the infected liver may due to hepatotoxicity induced by various drug intake (Xu et al., 2020). Moreover, in critical cases of SARS-CoV-2 patients associated with systemic inflammation, cytokine storm, and hypoxia as well as induce liver damage. The clinical manifestation of ACE2 in cholangiocytes determined by cholestasis aggregations with proliferated biliary cholangitis, GGT, and elevated levels of alkaline phosphatase. The comorbidities of liver cancer and liver cirrhosis induce the immunosuppression in severe infected $\mathrm{CoV}$ 
cases. Additionally, these comorbidities contribute to the additional impediments to the infected patients, such as hepatic encephalopathy, hemorrhage in the gastrointestinal tract, re-infection, liver failure, and mortality. The negotiated stage of the immune system is further required to find suitable immunotherapies for the surveillance of immunodeficient patients (Zhang et al., 2020).

\section{Post COVID-19 impact in cerebrum}

The SARS-CoV-2 infection induces the neurological impairment in the cerebrum, directly affects the neurotropic constituents in the brain, and the damages were confirmed by the presence of viral load in the cerebrospinal fluid (CSF) of patient's autopsy. However, the progressive disease phenomenon in the cerebrum is not well known. Recently, neurological symptoms such as cephalgia chronic coma, and paresthesia were observed in SARS-CoV-2 infected patients (36.4\%) with SARS symptoms (Mao et al., 2020). Furthermore, systemic edema and degeneration of neuronal tissue in the brain were examined in the ' 'patient's autopsy (Xu et al., 2020). The detrimental impacts of viral infections affect the central nervous system (CNS) causes cerebrum encephalitis reported in Beijing in March 2020 (Wu et al., 2020; Xiang et al., 2020). Additionally, the entry of the SARS RNA genome mediated through the olfactory nerve, thus distributes the viral population in the bloodstream and neuronal nervous system, consequently induces CNS disorders. The pathogenic interactions towards SARS-CoV-2 induce infectious, toxic encephalopathy, viral encephalitis, acute cerebrovascular disease, which existed through direct infection injury in the cerebrum, hypoxia damage, and ACE2 (Wu et al., 2020; Chau et al., 2004). However, the timely prediction of neurological complications in cerebrospinal fluid is an importan key factor for early prediction, which certainly helps for severely complicated ICU patients.

\section{SARS-CoV-2 entry assist via Neuropilin-1 transmit the infection pathway to CNS}

Noteworthy, the possible way of SARS-CoV-2 entry is mediated through the cellular ligand of neuropilin-1 (NRP1) penetrate via furin-cleaved S1-S2 subunits (Cantuti-Castelvetri et al., 2020). Moreover, the expression of NRP1 was found in endothelial and epithelial cells of the respiratory, and olfactory region that confirmed in autopsies patients. Furthermore, the higher tropism is regulated by NRP1, which allows the penetration of SARS-CoV-2 infection to the CNS proven in in vivo studies (Mao et al., 2020; Cantuti-Castelvetri et al., 2020; Teesalu et al., 2020; Pang et al., 2014). The associated symptoms of SARSCoV-2 viz., vascular endothelialitis, angiogenesis, and thrombosis associate the up-regulation of NRP1screation in capillary veins (Ackermann et al., 2020). The action of extracellular b1b2 domain NRP1 is inhibited by administrating the monoclonal blocking antibody to prevent the viral colony entries (CantutiCastelvetri et al., 2020).

\section{The herd immunity role in SARS-CoV-2}

Recently, to evaluate the seroprevalence of SARS-CoV-2, Pollan et al. (2020) stating that among 5\% of people had developed the immunity against SARS CoV-2. To acquired herd immunity, the virus spread should reach its maximum level to protect the uninfected people. The nationwide study conducted by Spain which proven the significant development of herd immunity, should reach 70 $90 \%$ of the population to protect uninfected people (Pollan et al., 2020) Interestingly, the prevalence of T-cell mediated antibodies was found higher in major affected areas compared to the coastal regions. However, the results mentioned above are not enough to determine herd immunity because of the lower estimated level of SARS-CoV-2.

\section{MAJOR OBSTACLES IN COVID19}

Approximately in the wide global population, the infection led by the 4 most common comparatively gentle human coronaviruses strains such as OC43, 229E, NL63, and HKU1. The respiratory flu-type origin of these strains like regular illness in the spring and winter months, during moderate climates. These SARS CoV-2 seroprevalence data suggest that exposure is common in early childhood, with around adults $90 \%$ being seropositive for 229E, OC43, and NL63 strains and HKU1 strain $60 \%$ being seropositive (https://www.covid19india.org).

In December 2019, no account recognized before the novel coronavirus (nCoV) strain founded rigorous respiratory associated illnesses identified in Wuhan, China, has been the commencement of this epidemic. Contrasting with additiona hCoVs, this nCoV2019 has a much bigger global spread and has been contaminating more persons than SARS-CoV that causes the MERS and SARS. These prior hCoVs were confirmed to have been invented in bats, and nCoV2019 is also suspected. The WHO declared SARS-CoV-2 as a worldwide epidemic on 11 March, 2020. As first such description, since 2009, the H1N1 influenza is a deadly disease. The novel SARS-CoV-2 has been spreading at a supersonic rate as a rigorous deadly disease, causing significant anxieties at all stages and now stated on every continent, not including Antarctica. In addition, to treat the SARS-CoV-2 dangerous effects, currently there are no proven therapeutic options or other drugs are available. Existing clinical managing includes disease obstacle, kind medicinal concern including automatic ventilator support, and supplemental oxygen. The number of people infected with SARS-CoV-2 continues to rise at a disturbing speed globally; the full amount and strictness of this outbreak remain unclear. It will continue to rise into an even more tedious pandemic, or it will burn itself remains to be seen. The developments were continuously monitored by the World Health Organization (WHO). As of $20^{\text {th }}$ June 2020, India had 4,11,750 confirmed tainted folks with 1,70,239 active SARS-CoV-2 cases admitted in hospitals, 13,277 deaths, and 2,28,183 recovering persons discharged and improving at home (https://www.covid19india.org).

Healthcare and research workers at all extents are hard-working to identify appropriate handlings and 'vaccines-'prevention' steps to control this deadly epidemic. SARS-CoV-2 is a novel; therefore, humans have no innate resistance to it, and researchers must begin from square one to develop a vaccine to instruct the immune system to defend itself from the virus. Across the world, various pharma companies and educational institutes are battled to grow a vaccine against SARS-CoV-2

There are some most important obstacles to defeat to produce a vaccine against SARS-CoV-2. Conventionally, vaccines would be made from a destabilized or destroyed virus. Newly, there has been a hub on using one to three molecules from the surface of a virus, rather than injecting a whole virus in a person. Researchers are performing clinical trials with a range of targets and formulations, few of which have never been used before in a licensed vaccine. At least six groups have already begun injecting their formulations into volunteers in safety trials, while others have in progress with the first more established testing in animals. All vaccines propose to expose the body to an antigen (whole or part of the virus) that does not basis the disease but will provoke an immune response that educates the immune system and potentially block or kill the virus if a person becomes infected with the virus in the future. The vaccines beneath lively trials depend mostly on viral parts or viruses.

Seven teams are raising vaccines using the virus itself, in a weakened form. Many available vaccines are made in this approach, for example, those against poliovirus and measles virus. Still, these types of vaccines require broad protection testing. Remarkably, in humans ongoing to test an inactivated version of SARS-CoV-2 by Sinovac Biotech, Beijing.

A virus such as an adenovirus or measles is hereditarily engineered so that it can make coronavirus proteins in the body. These viruses cannot cause disease because they are weakened. There are two types: those that can still reproduce within cells, and other is those that cannot because key genes have been disabled. The protein from the COV stimulates the immune response aiming to use genetic instructions viz., DNA or RNA, respectively. The nucleic acid is inserted into human cells, which then mix out copies of the virus protein-normally, these vaccines program the 'virus' spike protein.

Numerous researchers want to add coronavirus proteins directly into the body. Proteins fragments or protein shells that copy the coronavirus external coat can also be used. There is subjective evidence that the BCG vaccine offers some protection against $\mathrm{nCoV}$. At present, scientists are trying to attain something unimaginable a decade ago-creating a vaccine in opposition to a previously unknown virus rapidly enough to help end an existing occurrence. The current trials have been accelerated in unusual ways. However, even if we get a clear answer in the coming months, there is still this huge problem of manufacturing and scaling-up that needs to be addressed.

Scientists have fast-tracked each step in the detection and examining process and wish to have a vaccine against nCoV2019 ready in 10 to 18 months. Even this seemingly long timeline does not guarantee safety or efficacy in the larger human population. In the interim, we will need to keep on to stick on to social distancing, wearing of surgical mask with practice personal hygiene heightened to contain the virus load spread (https://health.economictimes.indiatimes.com/news/industry/scientificchallenges-for-a-safe-covid-19-vaccine/75595176).

The novel coronavirus is pandemic and severely affects the lower respiratory tract, which is an acute respiratory syndrome (Tufan $\boldsymbol{e t}$ al., 2020). The viruses and other infections involve suppressing the innate immune responses of the host to replicate the viral infections (Zhou et al., 2020). Pattern recognition receptor (PRR) is a surface receptor to recognize microbe-specific molecules that are called pathogen-associated molecular patterns (PAMPs) and include nucleic acids (such as bacterial or viral DNA or RNA). And viral infection in lungs is recognized by a surface receptor of intracellular Toll-like receptors (TLRs), which are involved in recognition of pathogen-associated molecular patterns (PAMPs) molecules (Zhang \& Mosser, 2008). The effectiveness of innate immune response against viral infection is mainly involved in the production of interferon (IFN) type I responses (Prompetchara, 2020) and also other proinflammatory cytokines, which makes the infection worsen in the host. SARS CoV2 directly enters the lungs through the alveoli epithelium type II receptor (ACE2). The ACE2 receptors are found in monocytes and macrophages when the SARS-CoV2 enters the host, and it will infect the monocytes and macrophages, which lead to affect the phagocytosis. The main characteristic function of viruses is that they can modulate the host microRNAs (miRNA), which plays a critical role in the replication of viral particles and immune responses. Recent studies have published that retinoic acid-inducible gene I (RIG-I) is found in the cytosol 
to recognize and binds to RNA viruses that initiates the signaling cascade and induces type-I IFN expression in the infected host which may help to reduces the severity of infection (Li et al., 2019). The main burden has been associated with social distancing, increased pressure on families and reduced access to support services. After the pandemic, economic recession and consequences of anxiety, stress and violence exposure may be predominant issues to meet in child and adolescent psychiatry (CAP) care (Fegert et al., 2020; Lambert et al., 2020; Hashem et al., 2020).

\section{TREATMENT}

The Indian Council of Medical Research (ICMR), from the Ministry of Health and Family Welfare (MHFW), has recommended chemoprophylaxis and hydroxychloroquine $(0.4 \mathrm{~g}$ twice on the first day, after that $0.4 \mathrm{~g}$ once a week) for non-symptomatic healthcare personnel treating patients with confirmed or suspected COVID-19, and for asymptomatic household confirmed cases peoples. Chloroquine (CQ) is a drug broadly used in the treatment of malarial and autoimmune diseases, also gives significant wide spectrum antiviral effects even against SARS-CoV-2 (Keyaerts et al., 2004; Savarino et al., 2006). A study reported that in in vitro study, the CQ has anti-SARS-CoV-2 activity (Wang $\boldsymbol{e}$ al., 2020). Gao et al. (2020) confirmed that in numerous associated clinical trials, CQ is effective for SARS-CoV-2 pneumonia. This therapy also results in the reduced disease course, improved pulmonary lesions, and excellent outcomes. National Commission of the People's Republic of China issued the CQ has been included in the strategy for the diagnosis and treatment of COVID-19 ( $^{\text {th }}$ edition) in which CQ is given the efficiency in clinical practice.

Hydroxychloroquine sulfate (HCQ) has a similar mechanism of action and chemical structure with CQ but with lower ocular toxicity (Lim et al., 2009), and it is also confirmed effective against SARS-CoV-2 in vitro (Liu et al., 2009). CQ and HCQ exert antiviral function through various mechanisms. CQ has been shown to interfere with the glycosylation process of Angiotensin-converting enzyme 2 (ACE2) in host cells, thereby the efficiency of the binding of the S protein with ACE2 inhibited, in turn disturbing the virus/cell fusion process (Savarino et al., 2006). Savarino et al. (2003) reported that virus entry into hos cells required the acidic cellular organelles $\mathrm{pH}$ in which, the CQ can increase $\mathrm{pH}$ Furthermore, Van Den Borne et al. (1997) study indirect antiviral activity, CQ and HCQ can satisfy major cytokine storms by decreasing cytokine production. Huang et al. (2020) noted that seriously ill SARS-CoV-2 patients have high cytokine concentrations, indicating that over-reactive immune responses worsen SARS-CoV-2. Hence, the immune-modulating activity of HCQ might partially account for its efficient control of SARS-CoV-2 infection. Due to the low cost, wide availability and potential efficacy for treating SARS-CoV-2 CQ and HCQ can be used as promising drugs. When treating SARS-CoV-2 infected patient with CQ and HCQ need to be administered with caution to prevent toxicity. However, Hoffmann et al. (2020) reported that chloroquine targets a pathway for viral activation that is not active in lung cells and is unlikely to protect against the spread of SARS-CoV-2 in and between patients. These medicines were initially suggested but later it was disapproved by FDA for the SARS-CoV2 patients.

Additionally, Gautret et al. (2020) demonstrated that open-label experiment in France showed that HCQ treatment was notably associated with viral load reduction/disappearance in SARS-CoV-2 patients and that its effect was reinforced by azithromycin. Although this study is an open-label study using a small sample size, the combination of HCQ with azithromycin could be a promising candidate for SARS-CoV-2 patients. Quite the reverse, Lane et al. (2020) described that a network cohort, multinational, and self-controlled case series study demonstrated that short-term HCQ is a safe treatment.

Favipiravir it is also known as Avigan and originally produced and permitted in Japan for the influenza virus infection epidemic, has an antiviral activity broad spectrum (Furuta et al., 2013). Once it goes into cells, it undergoes phosphorylation to convert into its active phosphorylated form (favipinavir-RTP), which potently inhibits viral RNA polymerase, thereby interfering with viral genome replication (Furuta et al., 2005). Favipiravir demonstrated effectiveness in inhibiting a wide range of viruses, including resistant influenza viruses and other RNA viruses, such as bunyaviruses, arenaviruses, and filoviruses (Delang et al., 2018). Previous studies have shown that favipiravir is efficacious against the Ebola virus in rodent/mouse models (Oestereich et al., 2014; Smither et al., 2014), while its effectiveness is unproven in humans (Sissoko et al., 2016). Favipiravir appears to be effective in SARS-CoV2. A total of 340 patients were conducted involving two clinical trials in Wuhan and Shenzhen.

Lopinavir/ritonavir (LPV-r) is a co-formulated human immunodeficiency virus (HIV)- exact protease inhibitor that provides as first-line therapy for HIV (Barragan \& Podzamczer, 2008). Attendant use of ritonavir could enlarge the plasma half-life of lopinavir through cytochrome P450 inhibition in the liver. During the 2003 SARS outbreak, LPV-r was reported to have in vitro effective activity against SARS-CoV-2 (Chu et al., 2004), and combination therapy of LPV-r and ribavirin offers good results in treating patients with SARS (Chu $\boldsymbol{e}$ al., 2004). Triple combination therapy with LPV-r, ribavirin, and IFN- $\alpha$ has shown clinical effectiveness against MERS. Notwithstanding, a recent open-label randomized study in Wuhan with 199 patients showed that LPV-r monotherapy did not produce any therapeutic benefits for SARS-CoV2 patients compared with standard supportive care, which might be caused by the higher throat viral loads in the LPV-r group, late treatment initiation, and concurrent pharmacologic interventions (Cao et al., 2020). The registered SARS-CoV-2 patients were critically ill, and LPV-r treatment might have been relatively late started.

Remdesivir, a nucleotide prodrug used to treat the Ebola virus (Siegel $\boldsymbol{e t}$ al., 2017) and subsequently demonstrating its efficacy in inhibiting coronaviruses such as MERS-CoV and SARS-CoV-2 in vitro (Sheahan et al., 2017), presents antiviral activity by interfering with RNA-dependent RNA polymerase, thereby attacking the virus's ability to replicate in the body (Agostini et al., 2018). A recent study reported that Remdesivir efficiently protected a human cell line against SARS-CoV-2 infection (Wang et al., 2020). Treatment with intravenous Remdesivir successfully improved the clinical state of the first U.S. COVID-19 patient (Holshue et al., 2020). Remdesivir is now being tested in several clinical trials planned to assess its effectiveness and protection for the treatment of COVID-19. An Israeli biotechnology company has claimed a $100 \%$ success rate in the first 10 patients treated with its drug as part of an early-stage clinical trial at Rambam Health Care Campus in Haifa(https://www.jpost.com/healthscience/10-serious-covid-patients-given-israeli-drug-leave-hospital-in-one-day69564?from=groupmessage).

\section{VACCINES}

There were six vaccines contestant namely adenoviral vector 5 (NCT04313127); mRNA (NCT04283461); chimpanzee adenoviral vector ChAdOx1 (NCT04324606); DNA (NCT04336410); a lentiviral vector (NCT04276896) and artificial antigen-presenting cells or aAPC (NCT04299724), which have entered the first phase of clinical trials for presenting SARS-CoV-2 antigens to assess their immunogenicity and safety. Even though the reality that most of these SARS-CoV-2 vaccines contestants are being examined in the first phase of the clinical trial, few are under experimental (DNA/RNA vaccines) and may have a longer expedition ahead to reach licensure. Existing information specifies that many vaccines express the SARS-CoV-2 spike (S) glycoprotein to deactivate the virus and prevent addition to the human angiotensin-converting enzyme II (ACE2) receptor, called co-receptor for viral entry of SARS-CoV-2 (Zhou et al., 2020)

The WHO reported the pneumococcal vaccine and Haemophilus influenza type B (Hib) vaccines do not protect against the new coronavirus. These two vaccines were not efficient against the novel SARS-CoV-2. Bacillus Calmette-Guerin (BCG) is a live attenuated vaccine, which is used against TB infection and is given for newborn 'children's and infants, to protect against pulmonary TB, meningitis, and also yellow fever (Starr et al., 1976). The studies have shown that the BCG vaccine is effective against pneumonia and influenza virus (Ohrui et al., 2005). BCG vaccine stimulates the production of cytokines to protect the host from infections. The BCG vaccine response has changed through epigenetic modification through innate immune responses as antiviral responses against the viral infection (Arts et al., 2018). Hence, WHO recommended that to continue the BCG vaccine for neonatal, which helps to protect and prevent the newborns against SARS-CoV-2. Through adaptive memory recognition, the BCG vaccine may help to protect against SARS-CoV-2 infection for older peoples. BCG vaccine has a role against to protect against the non-specific infection, which plays a protective role against the host (Moorlag et al., 2019; Shann, 2010).

\section{DIAGNOSTIC APPROACH}

In India, the SARS-CoV-2 virus provoked coronavirus disease 2019 has already infected close to six lakh peoples, causing the death of above 17,000 peoples. While these numbers are not comparable with values observed for the developed countries viz., USA, Spain, or Russia given the population of India, and the fact that the deadly disease is now in the severe stage of growth, the hazards of an infection that affects a large sector of the Indian population are real. The diagnostic measure should be established for this test. Control procedures should be taken for the peoples 'don't indicate SARS-CoV-2 disease.

A doubtful case is defined as one with fever \& sore throat, cough \& fever, fever \& diarrhea, who has a history of travel to containment zones or other areas of persistent local transmission or might have possible direct/indirect contact with patients with similar travel history or those with confirmed SARS-CoV-2 infection. Few cases may be non-symptomatic or even without a fever. The molecular test with a positive result is the confirmed case. Detailed analysis is by molecular tests on respiratory samples (nasopharyngeal swab/ throat swab/ sputum/ bronchoalveolar lavage and endotracheal aspirates). It must be kept in mind that the multiplex PCR panels currently available do not include the SARS CoV-2. At present commercial tests are also available. In SARS-CoV-2 diagnosis, the specimen type and duration are considered to play an important role. In India, the appropriate suspect case sample has to be sent to designated state reference laboratories in India or the National Institute of Virology, Pune. As the pandemic progresses, commercial tests will become available. In the early period, it was found that the respiratory specimens were positive, while serum was negative for the virus. In the early days, it has been suggested that patients had high levels of the virus, even with the mild symptoms (Chu et al., 2020). 


\section{Indirect method of confirmation}

In early disease, chest X-ray regularly shows bilateral infiltrates but may be normal. By using X-ray, lungs infection stage can be determined. The CT is more specific and sensitive. CT imaging generally shows ground-glass opacities, infiltrates, and subsegmental consolidation. It is also abnormal in patients with no clinical evidence of lower respiratory tract involvement or non-symptomatic patients. Abnormal CT scans have been used to identify SARS-CoV-2 in suspect cases with the negative molecular diagnosis; on repeat testing, many of these patients had positive molecular tests (Huilan et al., 2020).

A recombinant protein expressed the full-length SAR-CoV2 S1 protein was synthesized using $6 \mathrm{x}$ his tag by expressing them in human $293 \mathrm{~F}$ cells and Chinese hamster ovarian cells to obtain the glycosylation S1 surface protein of virus in its native conformation. The SAR-Cov2 6Xhis tag is purified using S1His protein with a molecular weight of $70 \mathrm{kDa}$ glycosylation helps in protein folding correctly but also contribute greatly to protein affinity of the receptors. A Chinese patent technology was used to increase the expression level of the fulllength recombinant SARS-CoV-2 S1 proteins up to $70 \mathrm{mg} / \mathrm{l}$. Using this expressed recombinant protein as the capturing antigen, they were able to perform a serology ELISA Kit on 412 normal human serum samples and 69 SARS-CoV-2 patients serum samples with a $97.5 \%$ specificity and $97.1 \%$ sensitivity. The antibody levels were increased for two weeks in hospitalized and discharged patients. Out of 276 asymptomatic medical staff, 28 were detected using this kit. The ELISA kit would help in screening health care to reduce hospital transfected SARS-Cov2 virus (Zhao et al., 2020).

China introduced the rapid test kit to detect the SARS-CoV-2 virus for less time consumption compared to the qPCR technique. This test is very easy for the testing and diagnosing of SARS-CoV-2, i.e., need drop-off patient's blood, whereas other diagnosis methods are not easier and time-saving. Hence India procured the rapid test kit from China, and they diagnosed the symptomatic and asymptomatic patients, but the results were false positive or negative. Falsepositive results were due to Indian populations were endemic, whereas Chinese populations were non-endemic. Hence kit results were not confirmatory and consistent. Further, the Indian Council of Medical Research (ICMR), New Delhi has banned the rapid test kit for diagnosing the SARS-CoV-2 patients in India However, the rapid kid test was refused globally due to false positive effects.
Recently, visual naked-eye and selective detection of SARS-CoV-2 causal virus using nucleocapsid phosphoprotein (N-gene) of SARS-CoV-2 targeted antisense oligonucleotide capped plasmonic nanoparticles without the necessity of any sophisticated instrumental techniques (Moitra et al., 2020).

\section{PREVENTION}

"Prevention is better than cure" is the proverb that is evocative for the current SARS-CoV-2 pandemic disease. Preventive measures are few who may need to pursue by the peoples to fight against the SARS-CoV-2. COVID-19 infected patients should be self-quarantined for 14 days from healthy peoples and family members. People should wear masks and wash their hands with sanitizer or soap often at least for 20 seconds. In the present scenario, peoples should avoid unnecessary travel to other countries/states that were SARS-CoV-2 pandemic School and college administrations should support online classes to avoid this deadly virus spread in the current situation. The most favorable situation would be COVID-19, automatically petering out as was the case with SARS in 2003 if nature gives us a chance.

\section{CONCLUDING REMARKS AND FUTURE PERSPECTIVES}

The novel SARS-CoV-2 has challenged the economic, medical, and public health infrastructure worldwide. This review describes the broad investigations of the SARS-CoV-2 genome, pathophysiological mechanism, and the fundamental aspects of the viral genome. Additionally, the inferences of post- SARS-CoV-2 and clinical manifestations of vital organ disease transmission strategies with their comorbidities are highlighted. Scheme 1 provides an elaborate illustration of the SARS-CoV-2 inferences, major obstacles in therapeutic strategies, and various methods of vaccine development. The list of recent vaccines and their respective role in the stimulation of immune responses were additionally discussed in Table 1. Finally, the preventive measures of SARS-CoV-2 have an important phenomenon through inhibiting the role of surface proteins, and dysfunctional immune status regulation may harmony to inhibit the infection transmission at the primary stage.

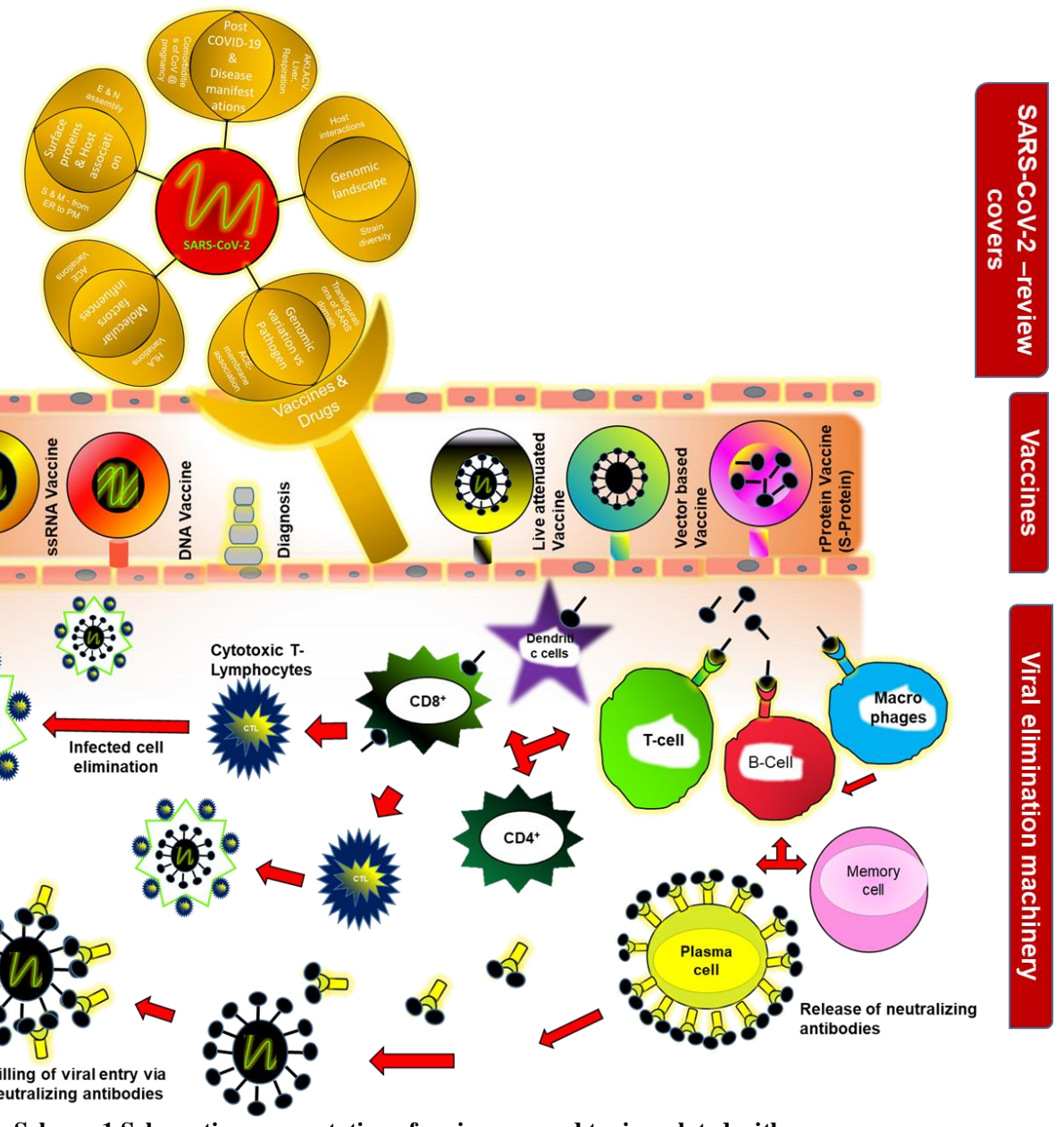

Scheme 1 Schematic representation of review covered topics related with 
Table 1 Recent vaccine profiles for COVID-19

\begin{tabular}{|c|c|c|c|c|c|}
\hline S.No. & Vaccines & Type/Technology & Phase & Country & References \\
\hline 1 & $\begin{array}{l}\text { Sputnik V and } \\
\text { Gam-COVID- } \\
\text { Vac Lyo }\end{array}$ & $\begin{array}{l}\text { Adenoviral-based } \quad \text { vaccine } \\
(\text { Adv5). }\end{array}$ & $\begin{array}{l}\text { Completed and } \\
\text { released }\end{array}$ & Russia & $\begin{array}{l}\text { https://www.coronavirustoday.com/corona } \\
\underline{\text { virus-vaccines }}\end{array}$ \\
\hline 2 & $\begin{array}{l}\text { Convidicea/Ad5- } \\
\text { nCoV COVID- } \\
19\end{array}$ & $\begin{array}{l}\text { CanSinoBIO's adenovirus-based } \\
\text { viral vector vaccine technology. } \\
\text { Ad5-nCoV vaccine is } \\
\text { genetically engineered with } \\
\text { defective adenovirus type } 5 \\
\text { vector to express SARS-CoV-2 } \\
\text { spike protein. }\end{array}$ & $\begin{array}{l}\text { Completed and } \\
\text { released }\end{array}$ & $\begin{array}{l}\text { CanSino Biologists and } \\
\text { China Military, } \\
\text { P R China }\end{array}$ & $\begin{array}{l}\text { https://www.coronavirustoday.com/corona } \\
\underline{\text { virus-vaccines }}\end{array}$ \\
\hline 3 & $\begin{array}{l}\text { AZD1222 } \\
\text { SARS-CoV-2 }\end{array}$ & $\begin{array}{l}\text { Developed based on a } \\
\text { chimpanzee adenovirus called } \\
\text { ChAdOx1.A single dose of } \\
\text { AZD1222 resulted in a 4-fold } \\
\text { increase in antibodies to the } \\
\text { SARS-CoV-2 virus spike } \\
\text { protein }\end{array}$ & $\begin{array}{l}\text { Completed and } \\
\text { released }\end{array}$ & $\begin{array}{l}\text { University of Oxford's } \\
\text { Jenner Institute, UK }\end{array}$ & Folegatti et al., 2020 \\
\hline 4 & $\begin{array}{l}\text { New Crown } \\
\text { COVID-19- } \\
\text { Sinopharm }\end{array}$ & $\begin{array}{l}\text { An inactivated new crown } \\
\text { candidate }\end{array}$ & $\begin{array}{l}\text { Completed and } \\
\text { released }\end{array}$ & $\begin{array}{l}\text { Wuhan Institute of } \\
\text { Biological Products, } \\
\text { National Pharmaceutical } \\
\text { Group, Sinopharm, and the } \\
\text { Wuhan Institute of } \\
\text { Virology, China and Abu } \\
\text { Dhabi, UAE }\end{array}$ & $\begin{array}{l}\text { https://www.precisionvaccinations.com/vac } \\
\underline{\text { cines/new-crown-covid-19-vaccine }}\end{array}$ \\
\hline 5 & $\begin{array}{l}\text { CoronaVac } \\
\text { SARS-CoV-2 }\end{array}$ & $\begin{array}{l}\text { Sinovac Biotech's Based on an } \\
\text { inactivated pathogen. }\end{array}$ & $\begin{array}{l}\text { Completed and } \\
\text { released }\end{array}$ & China & $\begin{array}{l}\text { https://www.coronavirustoday.com/corona } \\
\underline{\text { virus-vaccines }}\end{array}$ \\
\hline 6 & BNT162b2 & $\begin{array}{l}\text { BNT162b1 BNT162b2. } \\
\text { BNT162b2 encodes an } \\
\text { optimized spike glycoprotein }\end{array}$ & $\begin{array}{l}\text { Completed and } \\
\text { released }\end{array}$ & $\begin{array}{l}\text { Pfizer and BioNTech's } \\
\text { USA }\end{array}$ & $\begin{array}{l}\text { https://www.coronavirustoday.com/corona } \\
\underline{\text { virus-vaccines }}\end{array}$ \\
\hline 7 & $\begin{array}{l}\text { Moderna/mRNA } \\
-1273 \text { SARS- } \\
\text { CoV-2 }\end{array}$ & $\begin{array}{l}\text { Moderna's mRNA-1273 is } \\
\text { against the SARS-CoV-2 } \\
\text { converting for a prefusion } \\
\text { stabilized form of the Spike } \\
\text { protein. }\end{array}$ & $\begin{array}{l}\text { Completed and } \\
\text { released }\end{array}$ & Massachusettes, USA & Jackson et al., 2020 \\
\hline 8 & Ad26.COV2-S & $\begin{array}{l}\text { Ad26COVS1 (Ad26). Ad26 } \\
\text { vector-based vaccine. }\end{array}$ & $\begin{array}{l}\text { Completed and } \\
\text { released }\end{array}$ & $\begin{array}{l}\text { Johnson \& Johnson's } \\
\text { Janssen Vaccines \& } \\
\text { Prevention B.V. }\end{array}$ & Mercado et al., 2020 \\
\hline 9 & NVX-CoV2373 & $\begin{array}{l}\text { Novavxa's NVX-CoV2373 } \\
\text { created by using Novavax' } \\
\text { recombinant nanoparticle } \\
\text { technology to generate antigen } \\
\text { from spike (S) protein and } \\
\text { contains Novavax patented } \\
\text { saponin-based Matrix-M } \\
\text { adjuvant. }\end{array}$ & III & Maryland, USA & $\begin{array}{l}\underline{\text { https://novavax.com/download/files/2020.0 }} \\
\underline{\text { df }}\end{array}$ \\
\hline 10 & INO-4800 DNA & $\begin{array}{l}\text { Inovio's DNA made up of } \\
\text { boosted plasmid DNA are } \\
\text { restructured by a sequencing } \\
\text { technology }\end{array}$ & III & Pennsylvania & Smith et al., 2020 \\
\hline 11 & Sanofi and GSK & $\begin{array}{l}\text { Genetically similar proteins } \\
\text { from the surface proteins of the } \\
\text { virus, and the DNA sequence } \\
\text { encoding this antigen has been } \\
\text { combined into the DNA of the } \\
\text { baculovirus expression system. }\end{array}$ & II & USA-GSK & $\begin{array}{l}\text { https://www.coronavirustoday.com/corona } \\
\underline{\text { virus-vaccines }}\end{array}$ \\
\hline 12 & ZyCoV-D & Prophylactic vaccine-DNA & III & Zydus Cadila, India & $\underline{\text { https://www.clinicaltrialsarena.com/news/z }}$ \\
\hline 13 & $\begin{array}{l}\text { Vaxart COVID- } \\
19 \text { Oral Vaccine }\end{array}$ & Vaxart's is an oral H1 flu & I & USA & $\begin{array}{l}\text { https://www.coronavirustoday.com/corona } \\
\underline{\text { virus-vaccines }}\end{array}$ \\
\hline 14 & UQ COVID-19 & $\begin{array}{l}\text { UQ-CSL v451 COVID-19 } \\
\text { vaccine has shown that it elicits } \\
\text { a robust response towards the } \\
\text { virus }\end{array}$ & I (Declined) & $\begin{array}{c}\text { The University of } \\
\text { Queensland -Brisbane, } \\
\text { Australia. }\end{array}$ & $\begin{array}{l}\text { https://www.coronavirustoday.com/corona } \\
\underline{\text { virus-vaccines }}\end{array}$ \\
\hline 15 & $\begin{array}{l}\text { S-Trimer (SCB- } \\
\text { 2019) }\end{array}$ & $\begin{array}{l}\text { SCB-2019 is a recombinant } \\
\text { subunit vaccine }\end{array}$ & II & $\begin{array}{l}\text { The Sichuan 'Clover' } \\
\text { Biopharmaceuticals, } \\
\text { Australia-GSK, Dynavax } \\
\text { and The Sichuan 'Clover' } \\
\text { Biopharmaceuticals, China }\end{array}$ & $\begin{array}{l}\text { https://www.coronavirustoday.com/corona } \\
\underline{\text { virus-vaccines }}\end{array}$ \\
\hline 16 & $\begin{array}{l}\text { Beijing BBIBP- } \\
\text { CorV }\end{array}$ & $\begin{array}{l}\text { Inactivated coronavirus vaccine } \\
(2019-\mathrm{CoV}) \text { (Vero cells) }\end{array}$ & I & China & $\begin{array}{l}\text { https://www.coronavirustoday.com/corona } \\
\underline{\text { virus-vaccines }}\end{array}$ \\
\hline 17 & Covaxin & $\begin{array}{l}\text { From an asymptomatic COVID- } \\
19 \text { patient - viral strain is } \\
\text { isolated and inactivated }\end{array}$ & $\begin{array}{l}\text { Completed and } \\
\text { released }\end{array}$ & Bharat Biotech, Pune, India & $\begin{array}{l}\text { https://timesofindia.indiatimes.com/life- } \\
\text { style/health-fitness/health-news/bharat- } \\
\underline{\text { biotech-announces-indias-first-covid-19- }} \\
\text { vaccine-candidate-covaxin-with-dcgi- } \\
\text { approval-for-human-clinical- } \\
\text { trials/articleshow/76702913.cms }\end{array}$ \\
\hline
\end{tabular}


CureVac's is an mRNA vaccine candidate that utilizes

$18 \quad \mathrm{CVnCoV}$ nucleotides without chemical modifications in the native mRNA.

Combination of

Medicago's recombinant

Coronavirus Virus-Like

19 CoVLP

Particles (CoVLP) with GSK's

pandemic adjuvant system.

CoVLPs mimic the SARS-CoV-

2 structure.

Corvus is candidate for an

CPI-006 Novel

agonistic humanized monoclona

Immunotherapy antibody, named as CPI-006 will

be a potential immunotherapy

Altimmune, Inc.'s AdCOVID is

designed to protect the

$21 \quad$ AdCOVID

pulmonary from viral attack and protect from spreading of viral colony.

Valneava's VLA2001 is a Verocell, inactivated whole virus vaccine candidate targeting particles of SARS-CoV-2 with high S-protein density, combined with two adjuvants, alum and CpG 1018

23 CoviVac

$24 \quad$ Covidshield

inactivated

A separate version of the

AstraZeneca COVID-19

vaccine.

Chemically synthesized peptide antigens of SARS-CoV-2 proteins, conjugated to a carrier protein and adsorbed on an aluminum-containing adjuvant (aluminum hydroxide).

SARS-CoV-2 inactivated

vaccine

Single-dose adenoviral-based

vaccine deploying adenovirus vectors rAd26

A protein subunit vaccine using a dimeric form receptor-binding domain as the antigen, a harmless piece of the SARSCov-2 virus.

AnGes, Inc.'s AG0301 DNA vaccine candidate against COVID-19 is a plasmid DNA vaccine encoding the SARS-

CoV-2 spike protein that opens the door to infection. It is expected to prevent COVID-19 or the condition of COVID-19 patients from deteriorating.

Conjugate vaccine, in which the virus antigen, the receptor30 Soberana 02 binding domain (RBD), is chemically bound to the tetanus toxoid.

A recombinant vesicular stomatitis virus (VSV), an animal virus that does not cause disease in humans. The spike protein was replaced with that of SARS-CoV-2 that "results in rapid and potent induction of neutralizing antibodies against the SARS-CoV-2

COVAXX's UB-612 vaccine candidate is specifically designed to allow for the inclusion and presentation of multiple epitopes to elicit both B-cell (antibody) and T-cell (cellular) responses without
USA

III

The GSK and Medicago

Burlingame, California-

USA

Maryland, United States

I

Japan

Completed and released

Completed and released

Completed and released

III and released

Completed and released

Completed and released

III

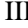

Cuba

AnGes Inc. and Osaka University, Japan

Israel Institute for Biological Research Indiana, Israel https://www.europeanpharmaceuticalrevie w.com/news/123096/curevac-recieves-e75 million-loan-for-vaccine-development-andmanufacturing-expansion/

https://www.coronavirustoday.com/corona virus-vaccines

https://www.coronavirustoday.com/corona virus-vaccines

https://www.coronavirustoday.com/corona virus-vaccines

https://www.coronavirustoday.com/corona virus-vaccines

https://www.coronavirustoday.com/covid19-vaccines

https://www.coronavirustoday.com/covid19-vaccines

https://www.coronavirustoday.com/covid$\underline{19 \text {-vaccines }}$

Zhang et al., 2020

https://www.coronavirustoday.com/covid19-vaccines

https://www.precisionvaccinations.com/vac cines/zf2001-covid-19-vaccine

https://www.precisionvaccinations.com/vac cines/ag0301-covid-19-vaccine

https://www.coronavirustoday.com/covid19-vaccines

https://www.coronavirustoday.com/covid19-vaccines 
enhancing COVID-19 disease.

Elixirgen Therapeutics's EXG-

5003 is a temperature-sensitive

self-replicating RNA vaccine

expressing the receptor-binding domain of the SARS-CoV-2 spike protein.

ImmunityBio hAd5 COVID-19

vaccine candidate targets the

inner nucleocapsid and the outer

34 hAd5-COVID-19 spike protein, engineered to activate both $\mathrm{T}$ cells and antibodies against the SARSCoV-2 coronavirus.

Virus-Like Particle (VLPs) of the coronavirus just 20 days

35 bacTRL-Spike after obtaining the SARS-CoV-2 (virus causing the COVID-19 disease) gene

Prophylactic vaccine based on optimized epitopes selected to induce a lasting sentinel $\mathrm{T}$ lymphocyte immune response against SARS-CoV-2, the virus that causes COVID-19.

The Receptor Binding Domain of the Spike Protein of SARS

COVID-19

Subunit Vaccine CoV-2 at three dose levels adjuvanted with CpG 1018 plus alum

I

Japan

USA

Australia

France

Biological E. Limited,

Hyderabad \& Texas

Children's Hospital, USA https://www.coronavirustoday.com/covid19-vaccines

https://www.coronavirustoday.com/covid19-vaccines

tps://www.coronavirustoday.com/covid19-vaccines

https://www.globenewswire.com/newsrelease/2020/11/05/2121346/0/en/OSEImmunotherapeutics-Provides-COVID-19 Vaccine-Update-on-CoVepiT-its-MultiTarget-and-Long-Lasting-VaccineCandidate.html

https://www.biologicale.com/news.html

\section{SARS-CoV-2}

Moreover, the viral pathogenicity and the resulting immune mechanism it elicits is an important measure for vaccine expansion. Currently, researchers are focusing on the study of correlation of the immune dysfunction in severely infected as well as healthy individuals, which is highly recommended for determining the SARS-CoV-2 responses. These studies will assist in finding the biomarkers to define an individual's health to preclude the viral infection progenies

\section{DECLARATION OF COMPETING INTEREST: None declared}

FUNDING: The authors are not supported by any funding agencies.

ETHICAL APPROVAL: Not required

\section{REFERENCES}

Ackermann, M., Verleden, S. E., Kuehnel, M., Haverich, A., Welte, T., Laenger F., ... \& Jonigk, D. (2020). Pulmonary vascular endothelialitis, thrombosis, and angiogenesis in Covid-19. New England Journal of Medicine, 383(2), 120-128. DOI: 10.1056/NEJMoa2015432

Agostini, M. L., Andres, E. L., Sims, A. C., Graham, R. L., Sheahan, T. P., Lu, X., ... \& Denison, M. R. (2018). Coronavirus susceptibility to the antiviral remdesivir (GS-5734) is mediated by the viral polymerase and the proofreading exoribonuclease. MBio, 9(2). https://doi.org/10.1128/mBio.00221-18

Akhmerov, A., \& Marbán, E. (2020). COVID-19 and the heart. Circulation research, 126(10),

$1443-1455$

https://doi.org/10.1161/CIRCRESAHA.120.317055

Almazán, F., DeDiego, M. L., Galán, C., Escors, D., Álvarez, E., Ortego, J., ... \& Enjuanes, L. (2006). Construction of a severe acute respiratory syndrome coronavirus infectious cDNA clone and a replicon to study coronavirus RNA synthesis. Journal of virology, 80(21), 10900-10906. https://dx.doi.org/10.1128\%2FJVI.00385-06

Andersen, K. G., Rambaut, A., Lipkin, W. I., Holmes, E. C., \& Garry, R. F. (2020). The proximal origin of SARS-CoV-2. Nature medicine, 26(4), 450-452. https://doi.org/10.1038/s41591-020-0820-9

Appenzeller, C., Andersson, H., Kappeler, F., \& Hauri, H. P. (1999). The lectin ERGIC-53 is a cargo transport receptor for glycoproteins. Nature cell biology, 1(6), 330-334. https://doi.org/10.1038/14020

Arbely, E., Khattari, Z., Brotons, G., Akkawi, M., Salditt, T., \& Arkin, I. T. (2004). A highly unusual palindromic transmembrane helical hairpin formed by SARS coronavirus E protein. Journal of molecular biology, 341(3), 769-779. https://doi.org/10.1016/j.jmb.2004.06.044

Arts, R. J., Moorlag, S. J., Novakovic, B., Li, Y., Wang, S. Y., Oosting, M., ... \& Netea, M. G. (2018). BCG vaccination protects against experimental vira infection in humans through the induction of cytokines associated with trained immunity. Cell host \& microbe, 23(1), 89-100. https://doi.org/10.1016/j.chom.2017.12.010
Assiri, A., Abedi, G. R., Al Masri, M., Bin Saeed, A., Gerber, S. I., \& Watson, J. T. (2016). Middle East respiratory syndrome coronavirus infection during pregnancy: a report of 5 cases from Saudi Arabia. Clinical Infectious Diseases, 63(7), 951-953. https://doi.org/10.1093/cid/ciw412

Bansal, M. (2020). Cardiovascular disease and COVID-19. Diabetes \& Metabolic Syndrome: Clinical Research \& Reviews, 14(3), 247-250. https://doi.org/10.1016/j.dsx.2020.03.013

Banu, S., Jolly, B., Mukherjee, P., Singh, P., Khan, S., Zaveri, L., \& Sowpati, D T. (2020, January). A distinct phylogenetic cluster of Indian SARS-CoV-2 isolates. In Open Forum Infectious Diseases. https://doi.org/10.1093/ofid/ofaa434 Bao, L., Deng, W., Huang, B., Gao, H., Liu, J., Ren, L., ... \& Qin, C. (2020). The pathogenicity of SARS-CoV-2 in hACE2 transgenic mice. Nature, 583(7818), 830-833. https://doi.org/10.1038/s41586-020-2312-y

Bao, Linlin, Wei Deng, Hong Gao, Chong Xiao, Jiayi Liu, Jing Xue, Qi Lv et al. "Lack of reinfection in rhesus macaques infected with SARS-CoV-2." BioRxiv (2020). doi: https://doi.org/10.1101/2020.03.13.990226

Barragan, P., \& Podzamczer, D. (2008). Lopinavir/ritonavir: a protease inhibitor for HIV-1 treatment. Expert opinion on pharmacotherapy, 9(13), 2363-2375. https://doi.org/10.1517/14656566.9.13.2363

Batlle, D., Soler, M. J., Sparks, M. A., Hiremath, S., South, A. M., Welling, P. A., \& Swaminathan, S. (2020). Acute kidney injury in COVID-19: emerging evidence of a distinct pathophysiology. Journal of the American Society of Nephrology, 31(7), 1380-1383. DOI: https://doi.org/10.1681/ASN.2020040419

Baudoux, P., Carrat, C., Besnardeau, L., Charley, B., \& Laude, H. (1998). Coronavirus pseudoparticles formed with recombinant $\mathrm{M}$ and $\mathrm{E}$ proteins induce alpha interferon synthesis by leukocytes. Journal of virology, 72(11), 8636-8643. https://doi.org/10.1128/JVI.72.11.8636-8643.1998

Belouzard, S., Chu, V. C., \& Whittaker, G. R. (2009). Activation of the SARS coronavirus spike protein via sequential proteolytic cleavage at two distinct sites. Proceedings of the National Academy of Sciences, 106(14), 5871-5876. https://doi.org/10.1073/pnas.0809524106

Bhatraju, P. K., Ghassemieh, B. J., Nichols, M., Kim, R., Jerome, K. R., Nalla, A. K., ... \& Mikacenic, C. (2020). Covid-19 in critically ill patients in the Seattle region-case series. New England Journal of Medicine, 382(21), 2012-2022. DOI: 10.1056/NEJMoa2004500

Buchholz, U. J., Bukreyev, A., Yang, L., Lamirande, E. W., Murphy, B. R. Subbarao, K., \& Collins, P. L. (2004). Contributions of the structural proteins of severe acute respiratory syndrome coronavirus to protective immunity. Proceedings of the National Academy of Sciences, 101(26), 9804-9809. https://doi.org/10.1073/pnas.0403492101

Cantuti-Castelvetri, L., Ojha, R., Pedro, L. D., Djannatian, M., Franz, J., Kuivanen, S., ... \& Simons, M. (2020). Neuropilin-1 facilitates SARS-CoV-2 cell entry and provides a possible pathway into the central nervous system. BioRxiv. https://doi.org/10.1101/2020.06.07.137802

Cao, B., Wang, Y., Wen, D., Liu, W., Wang, J., Fan, G., ... \& Wang, C. (2020) A trial of lopinavir-ritonavir in adults hospitalized with severe Covid-19. New England Journal of Medicine. DOI: 10.1056/NEJMoa2001282

Cavanagh D (2004) Coronaviruses and toroviruses. In: AJ Zuckerman JE Banatvala, PD Griffiths, JR Pattison, BD Schoub (eds): Principles and Practice of 
Clinical Virology, 5th ed., John Wiley \& Sons Ltd, Chichester, 379-397 https://doi.org/10.1099/vir.0.19424-0

Chai, X., Hu, L., Zhang, Y., Han, W., Lu, Z., Ke, A., ... \& Lan, F. (2020) Specific ACE2 expression in cholangiocytes may cause liver damage after 2019nCoV infection. biorxiv. https://doi.org/10.1101/2020.02.03.931766

Chan, J. F. W., To, K. K. W., Tse, H., Jin, D. Y., \& Yuen, K. Y. (2013). Interspecies transmission and emergence of novel viruses: lessons from bats and birds. Trends in microbiology, 21(10), 544-555. https://doi.org/10.1016/j.tim.2013.05.005

Chan, K. A., Tang, N. L., Hui, D. S., Chung, G. T., Wu, A. K., Chim, S. S., ... \& Lo, Y. D. (2005). Absence of association between angiotensin converting enzyme polymorphism and development of adult respiratory distress syndrome in patients with severe acute respiratory syndrome: a case control study. BMC infectious diseases, 5(1), 1-6. https://doi.org/10.1186/1471-2334-5-26

Chau, T. N., Lee, K. C., Yao, H., Tsang, T. Y., Chow, T. C., Yeung, Y. C., ... \& Lai, C. L. (2004). SARS-associated viral hepatitis caused by a novel coronavirus: report of three cases. Hepatology, 39(2), 302-310. doi: 10.1002/hep.20111.

Chen, Y., Liu, Q., \& Guo, D. (2020). Emerging coronaviruses: genome structure, replication, and pathogenesis. Journal of medical virology, 92(4), 418-423. https://doi.org/10.1002/jmv.25681

Chu, C. M., Cheng, V. C. C., Hung, I. F. N., Wong, M. M. L., Chan, K. H., Chan, K. S., ... \& Yuen, K. Y. (2004). Role of lopinavir/ritonavir in the treatment of SARS: initial virological and clinical findings. Thorax, 59(3), 252-256. http://dx.doi.org/10.1136/thorax.2003.012658

Chu, D. K., Pan, Y., Cheng, S. M., Hui, K. P., Krishnan, P., Liu, Y., ... \& Poon, L. L. (2020). Molecular diagnosis of a novel coronavirus (2019-nCoV) causing an outbreak of pneumonia. Clinical chemistry, 66(4), 549-555. https://doi.org/10.1093/clinchem/hvaa029

Corse, E., \& Machamer, C. E. (2002). The cytoplasmic tail of infectious bronchitis virus E protein directs Golgi targeting. Journal of virology, 76(3), 1273-1284. https://dx.doi.org/10.1128\%2FJVI.76.3.1273-1284.2002

Covid India (2020) https://www.covid19india.org

COVID-19 Host Genetics Initiative. (2020). The COVID-19 Host Genetics Initiative, a global initiative to elucidate the role of host genetic factors in susceptibility and severity of the SARS-CoV-2 virus pandemic. European Journa of Human Genetics, 28(6), 715. https://dx.doi.org/10.1038\%2Fs41431-020-0636-

De Haan, C. A., De Wit, M., Kuo, L., Montalto-Morrison, C., Haagmans, B. L., Weiss, S. R., ... \& Rottier, P. J. (2003). The glycosylation status of the murine hepatitis coronavirus $\mathrm{M}$ protein affects the interferogenic capacity of the virus in vitro and its ability to replicate in the liver but not the brain. Virology, 312(2), 395-406. https://doi.org/10.1016/S0042-6822(03)00235-6

De Haan, C. A., Kuo, L., Masters, P. S., Vennema, H., \& Rottier, P. J. (1998). Coronavirus particle assembly: primary structure requirements of the membrane protein. Journal of virology, 72(8), 6838-6850. https://doi.org/10.1128/JVI.72.8.6838-6850.1998

De Haan, C. A., Stadler, K., Godeke, G. J., Bosch, B. J., \& Rottier, P. J. (2004) Cleavage inhibition of the murine coronavirus spike protein by a furin-like enzyme affects cell-cell but not virus-cell fusion. Journal of virology, 78(11), 6048-6054. https://doi.org/10.1128/JVI.78.11.6048-6054.2004

Delang, L., Abdelnabi, R., \& Neyts, J. (2018). Favipiravir as a potential countermeasure against neglected and emerging RNA viruses. Antiviral research, 153, 85-94. doi: 10.1016/j.antiviral.2013.09.015.

Delmas, B., Gelfi, J., L'Haridon, R., Sjöström, H., \& Laude, H. (1992) Aminopeptidase $\mathrm{N}$ is a major receptor for the enteropathogenic coronavirus TGEV. Nature, 357(6377), 417-420. https://doi.org/10.1038/357417a0

Deng, X., Zhang, S., Jin, K., Li, L., Gu, W., Liu, M., \& Zhou, L. (2015) Angiotensin-converting enzyme I/D polymorphism and acute respiratory distress syndrome. Journal of the Renin-Angiotensin-Aldosterone System, 16(4), 780786. https://doi.org/10.1177\%2F1470320315576255

Diao, B., Feng, Z., Wang, C., Wang, H., Liu, L., Wang, C., ... \& Chen, Y. (2020). Human kidney is a target for novel severe acute respiratory syndrome coronavirus 2 (SARS-CoV-2) infection. MedRxiv. https://doi.org/10.1101/2020.03.04.20031120

Du, L., He, Y., Zhou, Y., Liu, S., Zheng, B. J., \& Jiang, S. (2009). The spike protein of SARS-CoV - a target for vaccine and therapeutic development. Nature Reviews Microbiology, 7(3), 226-236. https://doi.org/10.1038/nrmicro2090

Enjuanes, L., Almazán, F., Sola, I., \& Zuñiga, S. (2006). Biochemical aspects of coronavirus replication and virus-host interaction. Annu. Rev. Microbiol., 60 211-230. https://doi.org/10.1146/annurev.micro.60.080805.142157

Fang, Y., Zhang, H., Xie, J., Lin, M., Ying, L., Pang, P., \& Ji, W. (2020). Sensitivity of chest CT for COVID-19: comparison to RT-PCR. Radiology, 296(2), E115-E117. https://doi.org/10.1148/radiol.2020200432

Fegert, J. M., Vitiello, B., Plener, P. L., \& Clemens, V. (2020). Challenges and burden of the Coronavirus 2019 (COVID-19) pandemic for child and adolescent mental health: a narrative review to highlight clinical and research needs in the acute phase and the long return to normality. Child and adolescent psychiatry and mental health, 14, 1-11. https://doi.org/10.1186/s13034-020-00329-3

Findings from investigation and analysis of re-positive cases. Division of Risk assessment and International cooperation. https://www.cdc.go.kr/board/board.es?mid=a30402000000\&bid=0030 Updated 21 May 2020

Fischer, W. B. (Ed.). (2007). Viral Membrane Proteins: Structure, Function, and Drug Design (Vol. 1). Springer Science \& Business Media.. DOI:10.1007/0-38728146-0

Folegatti, P. M., Ewer, K. J., Aley, P. K., Angus, B., Becker, S., BelijRammerstorfer, S., ... \& Hamlyn, J. (2020). Safety and immunogenicity of the ChAdOx1 nCoV-19 vaccine against SARS-CoV-2: a preliminary report of a phase $1 / 2$, single-blind, randomised controlled trial. The Lancet, 396(10249), 467-478. doi: 10.1016/S0140-6736(20)31604-4

Forster, P., Forster, L., Renfrew, C., \& Forster, M. (2020). Phylogenetic network analysis of SARS-CoV-2 genomes. Proceedings of the National Academy of Sciences, 117(17), 9241-9243. https://doi.org/10.1073/pnas.2004999117

Furuta, Y., Gowen, B. B., Takahashi, K., Shiraki, K., Smee, D. F., \& Barnard, D. L. (2013). Favipiravir (T-705), a novel viral RNA polymerase inhibitor. Antiviral research, 100(2), 446-454. doi: 10.1016/j.antiviral.2013.09.015

Furuta, Y., Takahashi, K., Kuno-Maekawa, M., Sangawa, H., Uehara, S., Kozaki, K., ... \& Shiraki, K. (2005). Mechanism of action of T-705 against influenza virus. Antimicrobial agents and chemotherapy, 49(3), 981-986. doi 10.1128/AAC.49.3.981-986.2005.

Gao, J., Tian, Z., \& Yang, X. (2020). Breakthrough: Chloroquine phosphate has shown apparent efficacy in treatment of COVID-19 associated pneumonia in clinical studies. Bioscience trends. https://doi.org/10.5582/bst.2020.01047

Gard, P. R. (2010). Implications of the angiotensin converting enzyme gene insertion/deletion polymorphism in health and disease: a snapshot review. International journal of molecular epidemiology and genetics, 1(2), 145. http://www.ijmeg.org/IJMEG912003A.html

Gautret, P., Lagier, J. C., Parola, P., Meddeb, L., Mailhe, M., Doudier, B., ... \& Raoult, D. (2020). Hydroxychloroquine and azithromycin as a treatment of COVID-19: results of an open-label non-randomized clinical trial. International journal of antimicrobial agents, 56(1), 105949. https://doi.org/10.1016/j.ijantimicag.2020.105949

Godri Pollitt, K. J., Peccia, J., Ko, A. I., Kaminski, N., Dela Cruz, C. S., Nebert, D. W., ... \& Vasiliou, V. (2020). COVID-19 vulnerability: the potential impact of genetic susceptibility and airborne transmission. Human genomics, 14, 1-7. https://doi.org/10.1186/s40246-020-00267-3

Guo, Y. R., Cao, Q. D., Hong, Z. S., Tan, Y. Y., Chen, S. D., Jin, H. J., ... \& Yan, Y. (2020). The origin, transmission and clinical therapies on coronavirus disease 2019 (COVID-19) outbreak-an update on the status. Military Medical Research, 7(1), 1-10. https://doi.org/10.1186/s40779-020-00240-0

Gurwitz, D. (2020). Angiotensin receptor blockers as tentative SARS-CoV-2 therapeutics. Drug development research, 81(5), 537-540. https://doi.org/10.1002/ddr.21656

Hashem, H., Abufaraj, M., Tbakhi, A., \& Sultan, I. (2020). Obstacles and Considerations Related to Clinical Trial Research During the COVID-19 Pandemic. Frontiers in Medicine, https://dx.doi.org/10.3389\%2Ffmed.2020.598038

Hiscox, J. A., Wurm, T., Wilson, L., Britton, P., Cavanagh, D., \& Brooks, G. (2001). The coronavirus infectious bronchitis virus nucleoprotein localizes to the nucleolus. Journal of Virology, 75(1), 506-512. https://doi.org/10.1128/JVI.75.1.506-512.2001

Hoffmann, M., Kleine-Weber, H., Schroeder, S., Krüger, N., Herrler, T., Erichsen, S., ... \& Pöhlmann, S. (2020). SARS-CoV-2 cell entry depends on ACE2 and TMPRSS2 and is blocked by a clinically proven protease inhibitor. cell, 181(2), 271-280. https://doi.org/10.1016/i.cell.2020.02.052

Hoffmann, M., Mösbauer, K., Hofmann-Winkler, H., Kaul, A., Kleine-Weber, H., Krüger, N., ... \& Pöhlmann, S. (2020). Chloroquine does not inhibit infection of human lung cells with SARS-CoV-2. Nature, 585(7826), 588-590. https://doi.org/10.1038/s41586-020-2575-3

Hofmann, H., Geier, M., Marzi, A., Krumbiegel, M., Peipp, M., Fey, G. H., ... \& Pöhlmann, S. (2004). Susceptibility to SARS coronavirus S protein-driven infection correlates with expression of angiotensin converting enzyme 2 and infection can be blocked by soluble receptor. Biochemical and biophysical $\begin{array}{lll}\text { research communications, } & \text { 319(4), }\end{array}$ https://doi.org/10.1016/j.bbrc.2004.05.114

Holshue, M. L., DeBolt, C., Lindquist, S., Lofy, K. H., Wiesman, J., Bruce, H., .. \& Pillai, S. K. (2020). First case of 2019 novel coronavirus in the United States. New England Journal of Medicine. DOI: 10.1056/NEJMoa2001191 https://kjfy.meetingchina.org/msite/news/show/cn/3337.html https://novavax.com/download/files/2020.08.04NVXCoV2373Phase1ClinicalRes ults.pdf (Accessed on 20/08/2020)

https://timesofindia.indiatimes.com/life-style/health-fitness/health-news/bharatbiotech-announces-indias-first-covid-19-vaccine-candidate-covaxin-with-dcgiapproval-for-human-clinical-trials/articleshow/76702913.cms(Accessed 20/08/2020)

https://www.biologicale.com/news.html (Accessed on 22/05/21)

https://www.clinicaltrialsarena.com/news/zydus-covid-vaccine-phaseii/(Accessed on $20 / 08 / 2020$ )

https://www.coronavirustoday.com/coronavirus-vaccines (Accessed on $22 / 05 / 2021$ 
https://www.coronavirustoday.com/covid-19-vaccines (Accessed on 22/05/2021) https://www.covid19hg.org/ (Accessed on 01 May 2020)

https://www.europeanpharmaceuticalreview.com/news/123096/curevac-recievese75-million-loan-for-vaccine-development-and-manufacturing-

expansion/(Accessed on 20/08/2020)

https://www.globenewswire.com/news-release/2020/11/05/2121346/0/en/OSEImmunotherapeutics-Provides-COVID-19-Vaccine-Update-on-CoVepiT-itsMulti-Target-and-Long-Lasting-Vaccine-Candidate.html (Accessed 22/05/2021)

https://www.jpost.com/health-science/10-serious-covid-patients-given-israelidrug-leave-hospital-in-one-day-669564?from=groupmessage https://www.precisionvaccinations.com/vaccines/ag0301-covid-19-vaccine (Accessed on 22/05/2021)

https://www.precisionvaccinations.com/vaccines/new-crown-covid-19vaccine(Accessed on 22/05/2021)

https://www.precisionvaccinations.com/vaccines/ub-612-covid-19vaccine(Accessed on 22/05/2021)

https://www.precisionvaccinations.com/vaccines/zf2001-covid-19vaccine(Accessed on 22/05/2021)

Huang, C., Wang, Y., Li, X., Ren, L., Zhao, J., Hu, Y., ... \& Cao, B. (2020). Clinical features of patients infected with 2019 novel coronavirus in Wuhan China. The lancet, 395(10223), 497-506. https://doi.org/10.1016/S01406736(20)30183-5

Itoyama, S., Keicho, N., Quy, T., Phi, N. C., Long, H. T., Van Ban, V., ... \& Sasazuki, T. (2004). ACE1 polymorphism and progression of SARS Biochemical and biophysical research communications, 323(3), 1124-1129. https://doi.org/10.1016/j.bbrc.2004.08.208

Jackson, L. A., Anderson, E. J., Rouphael, N. G., Roberts, P. C., Makhene, M., Coler, R. N., ... \& Beigel, J. H. (2020). An mRNA vaccine against SARS-CoV2 -preliminary report. New England Journal of Medicine. doi 10.1056/NEJMoa2022483

Jia, H. P., Look, D. C., Shi, L., Hickey, M., Pewe, L., Netland, J., ... \& McCray, P. B. (2005). ACE2 receptor expression and severe acute respiratory syndrome coronavirus infection depend on differentiation of human airway epithelia $\begin{array}{llll}\text { Journal of } & \text { virology, } & \text { 14614-14621. }\end{array}$ https://dx.doi.org/10.1128\%2FJVI.79.23.14614-14621.2005

Kaul, D. (2020). An overview of coronaviruses including the SARS-2 coronavirus-Molecular biology, epidemiology and clinical implications. Current medicine research and practice. https://doi.org/10.1016/j.cmrp.2020.04.001

Kenyon, C. (2020). The serostatus approach to fighting COVID-19. International $\begin{array}{llll}\text { Journal of Infectious Diseases, 94, 53-54. } & \end{array}$ https://doi.org/10.1016/j.ijid.2020.03.080

Keyaerts, E., Vijgen, L., Maes, P., Neyts, J., \& Van Ranst, M. (2004). In vitro inhibition of severe acute respiratory syndrome coronavirus by chloroquine Biochemical and biophysical research communications, 323(1), 264-268. https://doi.org/10.1016/j.bbrc.2004.08.085

Kirkcaldy, R. D., King, B. A., \& Brooks, J. T. (2020). COVID-19 and postinfection immunity: limited evidence, many remaining questions. Jama, 323(22), 2245-2246. doi:10.1001/jama.2020.7869

Krijnse-Locker, J., Parton, R. G., Fuller, S. D., Griffiths, G., \& Dotti, C. G. (1995). The organization of the endoplasmic reticulum and the intermediate compartment in cultured rat hippocampal neurons. Molecular Biology of the Cell, 6(10), 1315-1332. https://doi.org/10.1091/mbc.6.10.1315

Krokhin, O., Li, Y., Andonov, A., Feldmann, H., Flick, R., Jones, S., ... \& Standing, K. G. (2003). Mass spectrometric characterization of proteins from the SARS virus: a preliminary report. Molecular \& Cellular Proteomics, 2(5), 346356. https://doi.org/10.1074/mcp.M300048-MCP200

Lai, M. M., \& Cavanagh, D. (1997). The molecular biology of coronaviruses Advances in virus research, 48, 1-100. https://doi.org/10.1016/S00653527(08)60286-9

Lambert, H., Gupte, J., Fletcher, H., Hammond, L., Lowe, N., Pelling, M., ... \& Shanks, K. (2020). COVID-19 as a global challenge: towards an inclusive and sustainable future. The Lancet Planetary Health, 4(8), e312-e314. https://doi.org/10.1016/S2542-5196(20)30168-6

Lane, J. C., Weaves, J., Kostka, K., Alser, O., Prats-Uribe, A., NEWBY, D., \& Prieto-Alhambra, D. (2020). Safety of hydroxychloroquine, alone and in combination with azithromycin, in light of rapid wide-spread use for COVID-19. a multinational, network cohort and self-controlled case series study. MedRXiv. https://doi.org/10.1101/2020.04.08.20054551

Li, F. (2016). Structure, function, and evolution of coronavirus spike proteins. Annual review of virology, 3, 237-261. https://doi.org/10.1146/annurevvirology-110615-042301

Li, F., Li, W. Farzan, M. \& Harrison, S. C. (2005). Structure of SARS coronavirus spike receptor-binding domain complexed with receptor. Science, 309(5742), 1864-1868. DOI: $10.1126 /$ science. 1116480

Li, S., Fu, B., \& Meshram, C. D. (2019). Innate immune and inflammatory responses to respiratory viruses. https://doi.org/10.1155/2019/3146065

Lim, H. S., Im, J. S., Cho, J. Y., Bae, K. S., Klein, T. A., Yeom, J. S., ... \& Park, J. W. (2009). Pharmacokinetics of hydroxychloroquine and its clinical implications in chemoprophylaxis against malaria caused by Plasmodium vivax.
Antimicrobial Agents and Chemotherapy, 53(4), 1468-1475 https://doi.org/10.1128/AAC.00339-08

Lim, K. P., \& Liu, D. X. (2001). The missing link in coronavirus assembly: retention of the avian coronavirus infectious bronchitis virus envelope protein in the pre-Golgi compartments and physical interaction between the envelope and membrane proteins. Journal of Biological Chemistry, 276(20), 17515-17523. https://doi.org/10.1074/jbc.M009731200

Lin, M., Tseng, H. K., Trejaut, J. A., Lee, H. L., Loo, J. H., Chu, C. C., ... \& Huang, C. H. (2003). Association of HLA class I with severe acute respiratory syndrome coronavirus infection. BMC Medical Genetics, 4(1), 1-7. https://doi.org/10.1186/1471-2350-4-9

Lippi, G., \& Plebani, M. (2020). Laboratory abnormalities in patients with COVID-2019 infection. Clinical Chemistry and Laboratory Medicine (CCLM), 58(7), 1131-1134. doi: 10.1515/cclm-2020-0198.

Liu, J., Cao, R., Xu, M., Wang, X., Zhang, H., Hu, H., ... \& Wang, M. (2020). Hydroxychloroquine, a less toxic derivative of chloroquine, is effective in inhibiting SARS-CoV-2 infection in vitro. Cell discovery, 6(1), 1-4. https://doi.org/10.1038/s41421-020-0156-0

Liu, Y., Chen, H., Tang, K., \& Guo, Y. (2020). Clinical manifestations and outcome of SARS-CoV-2 infection during pregnancy. The Journal of infection. https://doi.org/10.1016/j.jinf.2020.02.028

Luo, Z., Matthews, A. M., \& Weiss, S. R. (1999). Amino acid substitutions within the leucine zipper domain of the murine coronavirus spike protein cause defects in oligomerization and the ability to induce cell-to-cell fusion. Journal of virology, 73(10), 8152-8159. https://doi.org/10.1128/JVI.73.10.8152-8159.1999 Mao, L., Jin, H., Wang, M., Hu, Y., Chen, S., He, Q., ... \& Hu, B. (2020) Neurologic manifestations of hospitalized patients with coronavirus disease 2019 in Wuhan, China. JAMA neurology, 77(6), 683-690. doi:10.1001/jamaneurol.2020.1127

Martinez, M. A. (2020). Compounds with therapeutic potential against novel respiratory 2019 coronavirus. Antimicrobial agents and chemotherapy, 64(5) https://doi.org/10.1128/AAC.00399-20

Mercado, N. B., Zahn, R., Wegmann, F., Loos, C., Chandrashekar, A., Yu, J., .. $\&$ Barouch, D. H. (2020). Single-shot Ad26 vaccine protects against SARS-CoV2 in rhesus macaques. Nature, 586(7830), 583-588. doi: 10.1038/s41586-0202607-z.

Moitra, P., Alafeef, M., Dighe, K., Frieman, M. B., \& Pan, D. (2020). Selective naked-eye detection of SARS-CoV-2 mediated by $\mathrm{N}$ gene targeted antisense oligonucleotide capped plasmonic nanoparticles. ACS nano, 14(6), 7617-7627. https://doi.org/10.1021/acsnano.0c03822

Moore, J. B., \& June, C. H. (2020). Cytokine release syndrome in severe COVID-19. Science, 368(6490), 473-474. DOI: 10.1126/science.abb8925

Moorlag, S. J. C. F. M., Arts, R. J. W., Van Crevel, R., \& Netea, M. G. (2019) Non-specific effects of BCG vaccine on viral infections. Clinical microbiology and infection, 25(12), 1473-1478. https://doi.org/10.1016/j.cmi.2019.04.020

Mousavizadeh, L., \& Ghasemi, S. (2020). Genotype and phenotype of COVID19: Their roles in pathogenesis. Journal of Microbiology, Immunology and Infection. https://doi.org/10.1016/j.jmii.2020.03.022

Nal, B., Chan, C., Kien, F., Siu, L., Tse, J., Chu, K., ... \& Altmeyer, R. (2005) Differential maturation and subcellular localization of severe acute respiratory syndrome coronavirus surface proteins S, M and E. Journal of general virology, 86(5), 1423-1434. https://doi.org/10.1099/vir.0.80671-0

National Health and Family Planning Commission of China (NHPFC). March 04 2020. Chinese clinical guidance for COVID-19 pneumonia diagnosis and treatment (7th edition). https://doi.org/10.5582/bst.2020.01047

National Health Commission of Changde (China) (2020) Update on the epidemic situation of the novel coronavirus pneumonia in Changde on $10 \mathrm{Feb} 2020$ Changde: National Health Commission of Changde (China); 10 Feb 2020. Chinese. Available from: https://www.changde.gov.cn/zhdt/wjdt/ content 718989 .

Neuman, B. W., \& Buchmeier, M. J. (2016). Supramolecular architecture of the coronavirus particle. Advances in virus research, 96, 1-27. https://doi.org/10.1016/bs.aivir.2016.08.005

Nguyen, A., David, J. K., \& Maden, S. K. Human leukocyte antigen susceptibility map for SARS-CoV-2 [published online ahead of print April 17, 2020]. J Virol, 00510-20. https://doi.org/10.1128/JVI.00510-20

Oestereich, L., Lüdtke, A., Wurr, S., Rieger, T., Muñoz-Fontela, C., \& Günther, S. (2014). Successful treatment of advanced Ebola virus infection with T-705 (favipiravir) in a small animal model. Antiviral research, 105, 17-21. https://doi.org/10.1016/j.antiviral.2014.02.014

Ohrui, T., Nakayama, K., Fukushima, T., Chiba, H., \& Sasaki, H. (2005). Prevention of elderly pneumonia by pneumococcal, influenza and BCG vaccinations. Nihon Ronen Igakkai zasshi. Japanese journal of geriatrics, 42(1), 34-36. https://doi.org/10.3143/geriatrics.42.34

Oudit, G. Y., Kassiri, Z., Jiang, C., Liu, P. P., Poutanen, S. M., Penninger, J. M. \& Butany, J. (2009). SARS-coronavirus modulation of myocardial ACE2 expression and inflammation in patients with SARS. European journal of clinical investigation, 39(7), 618-625. doi: 10.1111/j.1365-2362.2009.02153.x.

Pan, X. W., Xu, D., Zhang, H., Zhou, W., Wang, L. H., \& Cui, X. G. (2020) Identification of a potential mechanism of acute kidney injury during the 
COVID-19 outbreak: a study based on single-cell transcriptome analysis. Intensive care medicine, 46(6), 1114-1116. https://doi.org/10.1007/s00134-02006026-1

Pang, H. B., Braun, G. B., Friman, T., Aza-Blanc, P., Ruidiaz, M. E., Sugahara, K. N., ... \& Ruoslahti, E. (2014). An endocytosis pathway initiated through neuropilin-1 and regulated by nutrient availability. Nature communications, 5(1), 1-12. https://doi.org/10.1038/ncomms5904

Payne, D. C., Iblan, I., Rha, B., Alqasrawi, S., Haddadin, A., Al Nsour, M., ... \& Al Abdallat, M. M. (2016). Persistence of antibodies against Middle East respiratory syndrome coronavirus. Emerging infectious diseases, 22(10), 1824 https://dx.doi.org/10.3201\%2Feid2210.160706

Peiris, J. S. M. (2012). Coronaviruses. Medical microbiology, 587. https://doi.org/10.1002/9781119350927.ch31

Pollán, M., Pérez-Gómez, B., Pastor-Barriuso, R., Oteo, J., Hernán, M. A., PérezOlmeda, M., ... \& de la Villa, A. V. (2020). Prevalence of SARS-CoV-2 in Spain (ENE-COVID): a nationwide, population-based seroepidemiological study. The Lancet, 396(10250), 535-544. https://doi.org/10.1016/S0140-6736(20)31483-5

Prabakaran, P., Xiao, X., \& Dimitrov, D. S. (2004). A model of the ACE2 structure and function as a SARS-CoV receptor. Biochemical and biophysical research communications, 314(1), 235-241. doi: 10.1016/j.bbrc.2003.12.081.

Procko, E. (2020). The sequence of human ACE2 is suboptimal for binding the S spike protein of SARS coronavirus 2. BioRxiv. https://doi.org/10.1101/2020.03.16.994236

Prompetchara, E., Ketloy, C., \& Palaga, T. (2020). Immune responses in COVID19 and potential vaccines: Lessons learned from SARS and MERS epidemic. Asian Pac J Allergy Immunol, 38(1), 1-9. DOI 10.12932/AP-200220-0772

Raamsman, M. J., Locker, J. K., De Hooge, A., De Vries, A. A., Griffiths, G., Vennema, H., \& Rottier, P. J. (2000). Characterization of the coronavirus mouse hepatitis virus strain A59 small membrane protein E. Journal of virology, 74(5), 2333-2342. https://doi.org/10.1128/JVI.74.5.2333-2342.2000

Sanjuán, R., \& Domingo-Calap, P. (2016). Mechanisms of viral mutation. Cellular and molecular life sciences, 73(23), 4433-4448. https://doi.org/10.1007/s00018-016-2299-6

Savarino, A., Boelaert, J. R., Cassone, A., Majori, G., \& Cauda, R. (2003) Effects of chloroquine on viral infections: an old drug against today's diseases. The Lancet infectious diseases, 3(11), 722-727. https://doi.org/10.1016/S14733099(03)00806-5

Savarino, A., Di Trani, L., Donatelli, I., Cauda, R., \& Cassone, A. (2006). New insights into the antiviral effects of chloroquine. The Lancet infectious diseases, 6(2), 67-69. https://doi.org/10.1016/S1473-3099(06)70361-9

Serfozo, P., Wysocki, J., Gulua, G., Schulze, A., Ye, M., Liu, P., ... \& Batlle, D. (2020). Ang II (angiotensin II) conversion to angiotensin-(1-7) in the circulation is POP (prolyloligopeptidase)-dependent and ACE2 (angiotensin-converting enzyme 2)-independent. Hypertension, 75(1), 173-182. https://doi.org/10.1161/HYPERTENSIONAHA.119.14071

Shang, J., Ye, G., Shi, K., Wan, Y., Luo, C., Aihara, H., ... \& Li, F. (2020). Structural basis of receptor recognition by SARS-CoV-2. Nature, 581(7807), 221-224. https://doi.org/10.1038/s41586-020-2179-y

Shann, F. (2010). The non-specific effects of vaccines. Archives of disease in childhood, 95(9), 662-667. http://dx.doi.org/10.1136/adc.2009.157537

Sheahan, T. P., Sims, A. C., Graham, R. L., Menachery, V. D., Gralinski, L. E., Case, J. B., ... \& Baric, R. S. (2017). Broad-spectrum antiviral GS-5734 inhibits both epidemic and zoonotic coronaviruses. Science translational medicine, 9(396). DOI: 10.1126/scitranslmed.aal3653

Shen, K., Yang, Y., Wang, T., Zhao, D., Jiang, Y., Jin, R., ... \& Gao, L. (2020) Diagnosis, treatment, and prevention of 2019 novel coronavirus infection in children: experts' consensus statement. World journal of pediatrics, 16(3), 223 231. https://doi.org/10.1007/s12519-020-00343-7

Shen, S., Law, Y. C., \& Liu, D. X. (2004). A single amino acid mutation in the spike protein of coronavirus infectious bronchitis virus hampers its maturation and incorporation into virions at the non permissive temperature. Virology, 326(2), 288-298. https://doi.org/10.1016/j.virol.2004.06.016

Siegel, D., Hui, H. C., Doerffler, E., Clarke, M. O., Chun, K., Zhang, L., ... \& Mackman, R. L. (2017). Discovery and synthesis of a phosphoramidate prodrug of a pyrrolo [2, 1-f][triazin-4-amino] adenine C-nucleoside (GS-5734) for the treatment of Ebola and emerging viruses. https://doi.org/10.1021/acs.jmedchem.6b01594

Simmons, G., Gosalia, D. N., Rennekamp, A. J., Reeves, J. D., Diamond, S. L., \& Bates, P. (2005). Inhibitors of cathepsin L prevent severe acute respiratory syndrome coronavirus entry. Proceedings of the National Academy of Sciences, 102(33), 11876-11881. https://doi.org/10.1073/pnas.0505577102

Simmons, G., Reeves, J. D., Rennekamp, A. J., Amberg, S. M., Piefer, A. J., \& Bates, P. (2004). Characterization of severe acute respiratory syndromeassociated coronavirus (SARS-CoV) spike glycoprotein-mediated viral entry. Proceedings of the National Academy of Sciences, 101(12), 4240-4245. https://doi.org/10.1073/pnas.0306446101

Sissoko, D., Laouenan, C., Folkesson, E., M'lebing, A. B., Beavogui, A. H., Baize, S., ... \& JIKI Study Group. (2016). Experimental treatment with favipiravir for Ebola virus disease (the JIKI Trial): a historically controlled, single-arm proof-of-concept trial in Guinea. PLoS medicine, 13(3), e1001967. https://doi.org/10.1371/journal.pmed.1001967

Smith, E. C., Blanc, H., Vignuzzi, M., \& Denison, M. R. (2013). Coronaviruse lacking exoribonuclease activity are susceptible to lethal mutagenesis: evidence for proofreading and potential therapeutics. PLoS Pathog, 9(8), e1003565. https://doi.org/10.1371/journal.ppat.1004342

Smith, E. C., Sexton, N. R., \& Denison, M. R. (2014). Thinking outside the triangle: replication fidelity of the largest RNA viruses. Annual review of virology, 1, 111-132. https://doi.org/10.1146/annurev-virology-031413-085507

Smith, T. R., Patel, A., Ramos, S., Elwood, D., Zhu, X., Yan, J., ... \& Broderick, K. E. (2020). Immunogenicity of a DNA vaccine candidate for COVID-19. Nature communications, 11(1), 1-13. doi: 10.1038/s41467-020-16505-0

Smither, S. J., Eastaugh, L. S., Steward, J. A., Nelson, M., Lenk, R. P., \& Lever, M. S. (2014). Post-exposure efficacy of oral T-705 (Favipiravir) against inhalational Ebola virus infection in a mouse model. Antiviral research, 104, 153 155. https://doi.org/10.1016/j.antiviral.2014.01.012

Sola, I., Almazan, F., Zuniga, S., \& Enjuanes, L. (2015). Continuous and discontinuous RNA synthesis in coronaviruses. Annual review of virology, 2 265-288. https://doi.org/10.1146/annurev-virology-100114-055218

Starr, S. E., Visintine, A. M., Tomeh, M. O., \& Nahmias, A. J. (1976). Effects of immunostimulants on resistance of newborn mice to herpes simplex type 2 infection. Proceedings of the Society for Experimental Biology and Medicine, 152(1), 57-60. https://doi.org/10.3181\%2F00379727-152-39327

Stawiski, E. W., Diwanji, D., Suryamohan, K., Gupta, R., Fellouse, F. A., Sathirapongsasuti, F., ... \& Seshagiri, S. (2020). Human ACE2 receptor polymorphisms predict SARS-CoV-2 susceptibility. BioRxiv. https://doi.org/10.1101/2020.04.07.024752

Su, H., Yang, M., Wan, C., Yi, L. X., Tang, F., Zhu, H. Y., ... \& Zhang, C. (2020). Renal histopathological analysis of 26 postmortem findings of patients with COVID-19 in China. Kidney international, 98(1), 219-227. https://doi.org/10.1016/j.kint.2020.04.003

Subbarao, K., \& Mahanty, S. (2020). Respiratory virus infections: understanding COVID-19.

https://doi.org/10.1016/j.immuni.2020.05.004

Tang, N., Li, D., Wang, X., \& Sun, Z. (2020). Abnormal coagulation parameter are associated with poor prognosis in patients with novel coronavirus pneumonia. Journal of thrombosis and haemostasis, 18(4), 844-847. https://doi.org/10.1111/jth.14768

Tang, X., Wu, C., Li, X., Song, Y., Yao, X., Wu, X., \& Lu, J. (2020). On the origin and continuing evolution of SARS-CoV-2. National Science Review, 7(6), 1012-1023. https://doi.org/10.1093/nsr/nwaa036

Teesalu, T., Sugahara, K. N., Kotamraju, V. R., \& Ruoslahti, E. (2009). C-end rule peptides mediate neuropilin-1-dependent cell, vascular, and tissue penetration. Proceedings of the National Academy of Sciences, 106(38), 16157 16162. https://doi.org/10.1073/pnas.0908201106

The economic times (2020)

https://health.economictimes.indiatimes.com/news/industry/scientific-challengesfor-a-safe-covid-19-vaccine/75595176 (Assessed on June 20th 2020).

Tian, C., Hromatka, B. S., Kiefer, A. K., Eriksson, N., Noble, S. M., Tung, J. Y., \& Hinds, D. A. (2017). Genome-wide association and HLA region fine-mapping studies identify susceptibility loci for multiple common infections. Nature communications, 8(1), 1-13. https://doi.org/10.1038/s41467-017-00257-5

Tijms, M. A., Van Der Meer, Y., \& Snijder, E. J. (2002). Nuclear localization of non-structural protein 1 and nucleocapsid protein of equine arteritis virus. Journa of General Virology, 83(4), 795-800. https://doi.org/10.1099/0022-1317-83-4795

To, K. K. W., Tsang, O. T. Y., Leung, W. S., Tam, A. R., Wu, T. C., Lung, D. C., \& Yuen, K. Y. (2020). Temporal profiles of viral load in posterior oropharyngeal saliva samples and serum antibody responses during infection by SARS-CoV-2: an observational cohort study. The Lancet Infectious Diseases, 20(5), 565-574. https://doi.org/10.1016/S1473-3099(20)30196-1

Tu, H., Tu, S., Gao, S., Shao, A., \& Sheng, J. (2020). The epidemiological and clinical features of COVID-19 and lessons from this global infectious public health event. Journal of Infection. http://dx.doi.org/10.1016/j.jinf.2020.04.011

Tufan, A., Güler, A. A., \& Matucci-Cerinic, M. (2020). COVID-19, immune system response, hyperinflammation and repurposing antirheumatic drugs Turkish journal of medical sciences, 50(SI-1), 620-632. https://dx.doi.org/10.3906\%2Fsag-2004-168

van Boheemen, S., de Graaf, M., Lauber, C., Bestebroer, T. M., Raj, V. S., Zaki, A. M., .. \& Fouchier, R. A. (2012). Genomic characterization of a newly discovered coronavirus associated with acute respiratory distress syndrome in humans. MBio, 3(6). https://doi.org/10.1128/mBio.00473-12

Van den Borne, B. E., Dijkmans, B. A., De Rooij, H. H., Le Cessie, S., \& Verweij, C. L. (1997). Chloroquine and hydroxychloroquine equally affect tumor necrosis factor-alpha, interleukin 6 , and interferon-gamma production by peripheral blood mononuclear cells. The Journal of rheumatology, 24(1), 55-60 https://dx.doi.org/10.1002\%2F14651858.CD013587

Vardhana, S. A., \& Wolchok, J. D. (2020). The many faces of the anti-COVID immune response. Journal of Experimental Medicine, 217(6). https://doi.org/10.1084/jem.20200678 
Venkatakrishnan, A. J., Puranik, A., Anand, A., Zemmour, D., Yao, X., Wu, X., ... \& Soundararajan, V. (2020). Knowledge synthesis of 100 million biomedical documents augments the deep expression profiling of coronavirus receptors. Elife, 9, e58040. DOI: 10.7554/eLife.58040

Vennema, H., Godeke, G. J., Rossen, J. W., Voorhout, W. F., Horzinek, M. C., Opstelten, D. J., \& Rottier, P. J. (1996). Nucleocapsid-independent assembly of coronavirus-like particles by co-expression of viral envelope protein genes. The EMBO journal, 15(8), 2020-2028. https://doi.org/10.1002/j.1460 2075.1996.tb00553.x

Walls, A. C., Park, Y. J., Tortorici, M. A., Wall, A., McGuire, A. T., \& Veesler, D. (2020). Structure, function, and antigenicity of the SARS-CoV-2 spike glycoprotein. Cell, 181(2), 281-292. https://doi.org/10.1016/j.cell.2020.02.058

Wang, L., Wang, Y., Ye, D., \& Liu, Q. (2020). Review of the 2019 novel coronavirus (SARS-CoV-2) based on current evidence. International journal of $\begin{array}{lll}\text { antimicrobial } & \text { agents, } & 105948 .\end{array}$ https://doi.org/10.1016/j.ijantimicag.2020.105948

Wang, M., Cao, R., Zhang, L., Yang, X., Liu, J., Xu, M., ... \& Xiao, G. (2020) Remdesivir and chloroquine effectively inhibit the recently emerged novel coronavirus (2019-nCoV) in vitro. Cell research, 30(3), 269-271. https://doi.org/10.1038/s41422-020-0282-0

Wang, P., Chen, J., Zheng, A., Nie, Y., Shi, X., Wang, W., ... \& Deng, H. (2004) Expression cloning of functional receptor used by SARS coronavirus. Biochemical and biophysical research communications, 315(2), 439-444 https://doi.org/10.1016/j.bbrc.2004.01.076

Wilson, P. C., Wu, H., Kirita, Y., Uchimura, K., Ledru, N., Rennke, H. G., ... \& Humphreys, B. D. (2019). The single-cell transcriptomic landscape of early human diabetic nephropathy. Proceedings of the National Academy of Sciences, 116(39), 19619-19625. https://doi.org/10.1073/pnas.1908706116

Wölfel, R., Corman, V. M., Guggemos, W., Seilmaier, M., Zange, S., Müller, M. A., ... \& Wendtner, C. (2020). Virological assessment of hospitalized patients with COVID-2019. Nature, 581(7809), 465-469. https://doi.org/10.1038/s41586020-2196-X

Woo, P. C., Huang, Y., Lau, S. K., \& Yuen, K. Y. (2010). Coronavirus genomics and bioinformatics analysis. Viruses, 2(8), 1804-1820. https://doi.org/10.3390/v2081803

Wrapp, D., Wang, N., Corbett, K. S., Goldsmith, J. A., Hsieh, C. L., Abiona, O., ... \& McLellan, J. S. (2020). Cryo-EM structure of the 2019-nCoV spike in the prefusion conformation. Science, 367(6483), 1260-1263. DOI 10.1126/science.abb2507

Wu, H., Uchimura, K., Donnelly, E. L., Kirita, Y., Morris, S. A., \& Humphreys, B. D. (2018). Comparative analysis and refinement of human PSC-derived kidney organoid differentiation with single-cell transcriptomics. Cell stem cell, 23(6), 869-881. https://doi.org/10.1016/i.stem.2018.10.010

Wu, L. P., Wang, N. C., Chang, Y. H., Tian, X. Y., Na, D. Y., Zhang, L. Y., ... \& Liang, G. D. (2007). Duration of antibody responses after severe acute respiratory syndrome. Emerging infectious diseases, 13(10), 1562 https://dx.doi.org/10.3201\%2Feid1310.070576

Wu, Y., Xu, X., Chen, Z., Duan, J., Hashimoto, K., Yang, L., ... \& Yang, C. (2020). Nervous system involvement after infection with COVID-19 and other coronaviruses. Brain, behavior, and immunity, 87, 18-22. https://doi.org/10.1016/j.bbi.2020.03.031

Wu, Z., \& McGoogan, J. M. (2020). Characteristics of and important lessons from the coronavirus disease 2019 (COVID-19) outbreak in China: summary of a report of 72314 cases from the Chinese Center for Disease Control and Prevention. Jama, 323(13), 1239-1242. doi:10.1001/jama.2020.2648

Wurm, T., Chen, H., Hodgson, T., Britton, P., Brooks, G., \& Hiscox, J. A (2001). Localization to the nucleolus is a common feature of coronavirus nucleoproteins, and the protein may disrupt host cell division. Journal of virology, 75(19), 9345-9356. https://doi.org/10.1128/JVI.75.19.9345-9356.2001 Xiang, P. X. X. M., Xu, X. M., Gao, L. L., Wang, H. Z., Xiong, H. F., \& Li, R. H. (2020). First case of 2019 novel coronavirus disease with encephalitis. ChinaXiv, 202003, 00015

Xiao, A. T., Tong, Y. X., \& Zhang, S. (2020). False negative of RT-PCR and prolonged nucleic acid conversion in COVID-19: Rather than recurrence. Journal of medical virology, 92(10), 1755-1756. https://doi.org/10.1002/jmv.25855

Xiao, X., Feng, Y., Chakraborti, S., \& Dimitrov, D. S. (2004). Oligomerization of the SARS-CoV S glycoprotein: dimerization of the N-terminus and trimerization of the ectodomain. Biochemical and biophysical research communications, 322(1), 93-99. https://doi.org/10.1016/j.bbrc.2004.07.084

Xie, X., Zhong, Z., Zhao, W., Zheng, C., Wang, F., \& Liu, J. (2020). Chest CT for typical coronavirus disease 2019 (COVID-19) pneumonia: relationship to negative RT-PCR testing. Radiology, 296(2), E41-E45. https://doi.org/10.1148/radiol.2020200343

Xing, Y., Mo, P., Xiao, Y., Zhao, O., Zhang, Y., \& Wang, F. (2020). Postdischarge surveillance and positive virus detection in two medical staff recovered from coronavirus disease 2019 (COVID-19), China, January to February 2020 Eurosurveillance, 25(10), 2000191. https://doi.org/10.2807/15607917.ES.2020.25.10.2000191

Xu, Z., Shi, L., Wang, Y., Zhang, J., Huang, L., Zhang, C., ... \& Wang, F. S. (2020). Pathological findings of COVID-19 associated with acute respiratory distress syndrome. The Lancet respiratory medicine, 8(4), 420-422 https://doi.org/10.1016/S2213-2600(20)30076-X

Yan, R., Zhang, Y., Li, Y., Xia, L., Guo, Y., \& Zhou, Q. (2020). Structural basis for the recognition of SARS-CoV-2 by full-length human ACE2. Science, 367(6485), 1444-1448. DOI: 10.1126/science.abb2762

Yao, H. P., Lu, X., Chen, Q., Xu, K., Chen, Y., Cheng, L., \& Li, L. (2020) Patient-derived mutations impact pathogenicity of SARS-CoV-2. CELL-D-2001124. https://dx.doi.org/10.2139/ssrn.3578153

Ye, M., Wysocki, J., William, J., Soler, M. J., Cokic, I., \& Batlle, D. (2006) Glomerular localization and expression of angiotensin-converting enzyme 2 and angiotensin-converting enzyme: implications for albuminuria in diabetes. Journa of the American Society of Nephrology, 17(11), 3067-3075. DOI: https://doi.org/10.1681/ASN.2006050423

Yeo, C., Kaushal, S., \& Yeo, D. (2020). Enteric involvement of coronaviruses: is faecal-oral transmission of SARS-CoV-2 possible?. The lancet Gastroenterology \& hepatology, 5(4), 335-337. https://doi.org/10.1016/S2468-1253(20)30048-0

Ying, W., Hao, Y., Zhang, Y., Peng, W., Qin, E., Cai, Y., ... \& He, F. (2004) Proteomic analysis on structural proteins of severe acute respiratory syndrome coronavirus. Proteomics, 4(2), 492-504. https://doi.org/10.1002/pmic.200300676 Young, B. E., Ong, S. W. X., Kalimuddin, S., Low, J. G., Tan, S. Y., Loh, J., \& Lye, D. C. (2020). Epidemiologic features and clinical course of patients infected with SARS-CoV-2 in Singapore. Jama, 323(15), 1488-1494. doi:10.1001/jama.2020.3204

Yu, P., Qi, F., Xu, Y., Li, F., Liu, P., Liu, J., ... \& Qin, C. (2020). Age-related rhesus macaque models of COVID-19. Animal models and experimental medicine, 3(1), 93-97. https://doi.org/10.1002/ame2.12108

Yuan, X., Yao, Z., Shan, Y., Chen, B., Yang, Z., Wu, J., \& Cong, Y. (2005). Nucleolar localization of non-structural protein $3 \mathrm{~b}$, a protein specifically encoded by the severe acute respiratory syndrome coronavirus. Virus research, 114(1-2), 70-79. https://doi.org/10.1016/j.virusres.2005.06.001

Zhang, C., Shi, L., \& Wang, F. S. (2020). Liver injury in COVID-19 management and challenges. The lancet Gastroenterology \& hepatology, 5(5), 428-430. https://doi.org/10.1016/S2468-1253(20)30057-1

Zhang, L., Lin, D., Sun, X., Curth, U., Drosten, C., Sauerhering, L., ... \& Hilgenfeld, R. (2020). Crystal structure of SARS-CoV-2 main protease provides a basis for design of improved $\alpha$-ketoamide inhibitors. Science, 368(6489), 409 412. DOI: $10.1126 /$ science.abb3405

Zhang, W., Du, R. H., Li, B., Zheng, X. S., Yang, X. L., Hu, B., ... \& Zhou, P. (2020). Molecular and serological investigation of 2019-nCoV infected patients: implication of multiple shedding routes. Emerging microbes \& infections, 9(1), 386-389. https://doi.org/10.1080/22221751.2020.1729071

Zhang, X., \& Mosser, D. M. (2008). Macrophage activation by endogenous danger signals. The Journal of Pathology: A Journal of the Pathological Society of Great Britain and Ireland, 214(2), 161-178. https://doi.org/10.1002/path.2284 Zhang, Y. J., Zeng, G., Pan, H. X., Li, C. G., Kan, B., Hu, Y. L., ... \& Zhu, F. C. (2020). Immunogenicity and safety of a SARS-CoV-2 inactivated vaccine in healthy adults aged 18-59 years: report of the randomized, double-blind, and placebo-controlled phase 2 clinical trial. medrxiv. https://doi.org/10.1101/2020.07.31.20161216

Zhao, J., Yuan, Q., Wang, H., Liu, W., Liao, X., Su, Y., ... \& Zhang, Z. (2020). Antibody responses to SARS-CoV-2 in patients with novel coronavirus disease 2019. Clinical infectious diseases, 71(16), 2027-2034. https://doi.org/10.1093/cid/ciaa344

Zhao, R., Li, M., Song, H., Chen, J., Ren, W., Feng, Y., ... \& Sun, L. (2020) Early detection of SARS-CoV-2 antibodies in COVID-19 patients as a serologic marker of infection. Clinical Infectious Diseases. https://doi.org/10.1093/cid/ciaa523

Zhou, F., Yu, T., Du, R., Fan, G., Liu, Y., Liu, Z., ... \& Cao, B. (2020). Clinical course and risk factors for mortality of adult inpatients with COVID-19 in Wuhan, China: a retrospective cohort study. The lancet, 395(10229), 1054-1062 https://doi.org/10.1016/S0140-6736(20)30566-3

Zhou, P., Yang, X. L., Wang, X. G., Hu, B., Zhang, L., Zhang, W., \& Shi, Z. L. (2020). A pneumonia outbreak associated with a new coronavirus of probable bat origin. nature, 579(7798), 270-273. https://doi.org/10.1038/s41586-020-2012-7

Zhou, Z., Ren, L., Zhang, L., Zhong, J., Xiao, Y., Jia, Z., ... \& Wang, J. (2020) Heightened innate immune responses in the respiratory tract of COVID-19 patients. Cell host \& microbe, 27(6), 883-890. https://doi.org/10.1016/j.chom.2020.04.017

Zhu, N., Zhang, D., Wang, W., Li, X., Yang, B., Song, J., \& Tan, W. (2020). A novel coronavirus from patients with pneumonia in China, 2019. New England journal of medicine. DOI: 10.1056/NEJMoa2001017

Ziebuhr, J. (2005). The coronavirus replicase. Coronavirus replication and reverse genetics, 57-94. https://doi.org/10.1007/3-540-26765-4_3 